\title{
Mangerment ANNALS
}

\section{Opportunity, motivation and ability to learn from failures and errors: Review, synthesis, and the way forward.}

\begin{tabular}{|r|l|}
\hline Journal: & Academy of Management Annals \\
\hline Manuscript ID & ANNALS-2016-0049.R4 \\
\hline Document Type: & Article \\
\hline Keywords: & $\begin{array}{l}\text { Organizational < COGNITION, Team < COGNITION, Organizational < } \\
\text { LEARNING, Group < LEARNING, Individual < LEARNING }\end{array}$ \\
\hline \multicolumn{2}{|l}{} \\
\hline
\end{tabular}

SCHOLARONE ${ }^{m}$

Manuscripts 


\title{
Opportunity, motivation and ability to learn from failures and errors:
}

\section{Review, synthesis and ways to move forward}

\author{
Kristina B. Dahlin*, You-Ta Chuang** \& Thomas J. Roulet*** \\ * University of Oxford ** York University *** King's College London
}

\begin{abstract}
Acknowledgment
The authors are grateful for valuable comments and support from Elizabeth George, the editor, as well as from two reviewers. The authors have also benefited from discussions with Joelle Evans, Kristin Bondesson, Linda Argote, Matt Cronin, Ned Welch, Shitij Kapur and any health care worker we encountered while working on the manuscript.
\end{abstract}

\begin{abstract}
While organizations and individuals tend to focus on learning from success, research has shown that failure can yield crucial insights in various contexts that range from small mistakes and errors, product recalls, accidents, and medical errors, to large-scale disasters. This review of the literature identifies three mechanisms - opportunity, motivation, and ability — through which individuals, groups and organizations learn from failure, and it bridges the gaps between different levels of analysis. Opportunity to learn from failure mostly takes the shape of more information about errors and failures that are generated by one's own and others' prior failures or near-failures. Motivation to learn from failure is hindered by punitive leaders and organizations. Finally, ability to learn from failure partly relies on inherent attitudes and characteristics; but can be further developed through thoughtful analysis and transfers of successful routines. Our review leads us to distinguish between erroneous versus correct processes and adverse versus successful outcomes to better understand the full gamut of events that are faced by organizations. We identify the existence of noisy learning environment, where spurious successes (when erroneous processes still lead
\end{abstract}


to successful outcomes) and spurious failures (when correct processes are combined with adverse outcomes) lower the opportunity to learn. Considering noisy learning situations is helpful when understanding the differences between slow- and fast-learning environments. We conclude our review by identifying a number of unexplored areas we hope scholars will address to better our understanding of failure learning.

\section{INTRODUCTION}

Sometimes we may learn more from a man's errors, than from his virtues. Henry Wadsworth Longfellow

Individuals and organizations repeatedly confront failures that range from small technical errors and mistakes to product breakdowns to large-scale disasters. Failure can stigmatize individual and organizational reputations, and it can be extremely costly for organizations and society. Failure is also more noticeable than success because negative information is more salient than positive information (Ito, Larsen, Smith \& Cacioppo, 1998). As a consequence, individuals and organizations strongly prefer success, which makes learning from failure difficult because both the reporting of errors and other failures as well as the correct analysis and response are risky and emotionally fraught. However, learning from failures is critical for both operational performance and safety — failure learning is necessary for quality improvements and efficiency gains in production processes, and systematic failure reporting and analyses have been key for reductions in transportation accidents and adverse events in hospitals. Because of failure's significance, the research on the topic spans many fields such as psychology (cf. Ellis \& Davidi, 2005; Hofmann \& Mark, 2006), organizational studies (cf. Reason, 1997; Zhao \& Olivera, 2006), strategic management (cf. Muehlfeld, Sahib, \& van Witteloostuijn, 2012), sociology (cf. Perrow, 1999), and health care management (cf. Hoff, Jameson, Hannan, \& Flink, 2004; Kohn, Corrigan, Donaldson, 1999). Importantly, failures provide valuable learning opportunities: individuals and organizations modify their practices 
to prevent similar future failures and to improve performance (Sitkin, 1992). Without examining failure learning, our understanding of success learning is also inherently biased (Baum \& Dahlin, 2007; Denrell, 2003). Recognizing the potential of failure to improve performance, recent studies on failure have begun to shift their focus from why and how failure occurs in organizations to how individuals and organizations do (or do not) learn from failure.

Failure learning has become a distinct area in the organizational learning literature, and it has attracted growing attention from scholars who seek to understand the phenomenon in various contexts such as product recalls (Haunschild \& Rhee, 2004), project failure (Shepherd, Patzelt, \& Wolfe, 2011), bankruptcies (Kim \& Miner, 2007), healthcare errors and incidents (Chuang et al. 2007; Vogus \& Sutcliffe, 2007), and accidents (Baum \& Dahlin, 2007; Haunschild \& Sullivan, 2002). The studies on failure learning cover multiple levels of analysis and draw from a variety of theoretical frames to understand how actors do (or do not) learn from failure. While an array of factors that affect failure learning has been identified, there is a lack of systematic integration across levels of analysis and settings; hence, the collective wisdom about how to best learn from failure is limited and fragmented. Importantly, the studies on failure learning borrow much from traditional learning studies, but the links and dissimilarities are not clearly understood. Studies that have attempted to combine success and failure learning lack conclusive findings and theory exploring how these events are related. To that end, there is a greater divide between traditional learning studies and failure learning studies than is currently being theorized.

We conduct a review of failure learning studies and synthesize them to better understand the underlying mechanisms that influence failure learning. We apply the framework of opportunity, motivation, and ability to integrate and discuss learning factors at the individual, group, and organizational levels. Specifically, opportunity represents a 
mechanism that provides information or sufficient time to analyze the cause-effect of failures; motivation captures different actors' willingness to act on failure information and to engage in failure learning activity; and ability represents actors' skills or knowledge base to change their actions based on failure information (Argote, 2012; Reinholt, Pedersen \& Foss, 2011). Mapping the studies of failure learning at multiple levels of analysis with this framework can generate new insights for future work.

We argue that it is important to clearly separate between processes and outcomes and to acknowledge that bad processes do not always lead to failed outcomes and, conversely, that correct processes might still result in failed outcomes. A traditional focus on "successful processes — successful outcomes" versus "failed processes—failed outcomes" overlooks the fact that "successful processes_-failed outcomes" and "failed processes_-successful outcomes" are common. We call these last two process-outcome combinations spurious failures and spurious successes. When they are common, these combinations produce noise in traditional learning processes that negatively affects opportunity, motivation, and ability to learn. A complete understanding of process-outcome relationships in organizational learning helps to address a fundamental critical question of why we see a systematic decrease in failures in one setting, whereas in another we do not. While the risk of dying in a car accident has diminished by $50 \%$ over the last 25 years, and the risk of train accidents has been reduced by $70 \%$ (NCSA, 2015; FRA, 2016), the risk of dying from a hospital error has increased by $350 \%{ }^{1}$ (Binder, 2013; Kohn, Corrigan \& Donaldson, 2000).

Below, we begin our review by defining failures and failure learning as well as errors and error learning, followed by a review of the failure and error learning literatures at three levels of analysis, clustering mechanisms under the opportunity-motivation-ability headings. We highlight the key constructs and mechanisms that can be identified as influencing learning

\footnotetext{
${ }^{1}$ Part of the increase is due to new definitions and better measurement of preventable hospital errors. The numbers are also challenged; however, overall it is clear that there is little to no improvement, which still demonstrates the contrast with transportation accidents.
} 
processes and outcomes. From there, we discuss how the four process-outcome combinations influence the opportunity, motivation, and ability that are associated with failure learning. Finally, synthesizing and assessing the literature as a whole, we identify the research challenges in failure learning and discuss the promising research opportunities that may advance our understanding of failure learning.

\section{DEFINING SCOPE: FAILURE, ERRORS, AND FAILURE LEARNING}

There is a literature on errors and another literature on failures in organizations. They are related, and many of the mechanisms and findings overlap. In fact, they often use the same definition for errors and failures, that they "deviate from expected and desired goals" (Rasmussen, 1982; Reason, 1990; Leape, 1974; Zhao \& Olivera, 2003; Sitkin, 1992). The literatures do also differ since errors are incorrectly executed tasks or routines (such as a train engineer who drives a train over the speed limit or a nurse who gives the incorrect medication to a patient), while failures are undesired performance outcomes (a train accident occurring instead of the train getting from point A to point B as planned; a patient who dies after surgery instead of leaving the hospital healthier than before entering it).

With regard to errors, they have been classified by Rasmussen (1982) into rule-based errors (breaking a known rule), skill-based errors (making a mistake or forgetting) and knowledge-based errors (not knowing enough). Another error typology is whether the error is action-based or related to decision-making (Lei, Naveh, \& Novikov, 2016; Zhao \& Olivera, 2006). Nevertheless, not all errors, mistakes or incidents necessarily lead to failure. Some errors and mistakes can even produce positive outcomes, such as the discovery of new organizational processes and innovation, or be too insignificant have any impact on an event's eventual success or failure (Cannon \& Edmondson, 2005). 
Failures may be caused by a combination of errors such as incorrectly executed routines and tasks, violations, risks, or chance factors (Frese \& Keith, 2015; Hofmann \& Frese, 2011). It can be avoidable or unavoidable, intentional or unintentional. It can involve human action and organizational processes and arrangements (e.g., Ramanujam \& Goodman, 2003; Reason, 1997).

We define error and failure learning as the process by which individuals, groups, or organizations identify error or failure events, analyze such events to find their causes, and search for and implement solutions to prevent similar errors or failures in the future. This definition is consistent with the definitions of learning in the organizational learning literature (Argote, 2012). The outcomes of error and failure learning can therefore include changes in understanding (Huber, 1991), behaviors (Chuang \& Baum, 2003; Ginsburg et al., 2009; Shepherd, Patzelt, \& Wolfe, 2011) or performance improvement (Cannon \& Edmondson, 2001; Dahlin \& Baum, 2007; Heimbeck, et al., 2003; Zhao, 2011).

We aimed to be inclusive, if not exhaustive, in identifying studies on error and failure learning and searched key management, health management and safety journals for relevant studies, focusing mostly but not exclusively on the period from year 2000. All identified articles were sorted by their level(s) of analysis. We reviewed the learning mechanisms in the articles and categorized them according to failure learning triggers, clustering them under three headings: opportunity to learn, motivation to learn, and ability to learn.

\section{OPPORTUNITY TO LEARN FROM FAILURE}

Opportunity to learn refers to the scope of information and the time that allows actors to learn from failure events. Information-based opportunity refers to the amount of information that is available about similar failure events because such events can provide information about failure causes (Argote, 2012). Time-based opportunity refers to the time that is given to 
actors to reflect upon failure events and to analyze the information that can be derived from the events to learn from them and the time in which to execute an action that is related to a failure learning activity (cf. Carroll, 1963). Information-based opportunities are usually studied by quantifying the amount of available information about similar failure events (number, frequency, recency), information access owing to group composition, organizational members' networks and information diffusion inside or between organizations. By contrast, time-based opportunity refers to how much time that is available to process information and/or carrying out a task (Carroll, 1963).

Information-based learning opportunities are often measured as one's own or others' prior experiences with similar failure events (counted as the of number of events or the number of cumulative events in previous time periods) and as how organizational structures and routines influence the diffusion of failure-learning-related information. Experience and its effect on learning are the most common empirical approach, and while this was first studied in production settings that range from classic cases of airplane construction to that of liberty ship builders (Wright 1936; Thompson, 2001) and learning curves, which refers to the idea that cumulative experience affects performance at a decreasing rate, the experience and its effect on learning have come to be applied across levels of analysis, and used across a large number of settings - among them failure learning.

Two different processes convert experiences into better performance: learning-by-doing and analytical learning. Learning-by-doing is mostly automatic and tacit, while analytical learning involves active decision-making that uses information about a prior event to reshape future routines (Thomson, 2012; Reason, 1990). Failure learning theories are much more concerned with the active decision-making theory, especially on the individual and group levels, while few organizational learning curve studies separate empirical and theoretically 
between learning by doing and analytical learning (see Lapré, Mukherjee \& Van Wassenhove, 2000; or Sinclair, Klepper \& Cohen, 2000 for exceptions). ${ }^{2}$

Time-based, or temporal, learning opportunities are concerned with the amount of time that an actor has to execute a routine or to process information about a routine that has gone wrong. Outside of the realm of student learning, relatively few studies have examined temporal mechanisms. Exceptions in failure learning a small number of studies that analyze the impact of workload and slack (Malone et al. 2007; Lawton, et al. 2012) and how the speed of assimilating and analyzing relevant information affects work processes and routines (Edmondson, et al. 2001). In addition, autonomy provides the mental and operational space that can allow individuals to prioritize their tasks, allowing them the time that they need to learn from failure (Kerr, 2009; Stern et al., 2008).

\section{Individual and group level opportunities to learn from failure}

A wide range of studies have examined how information-based and time-based opportunities lead to failure learning. While some learning opportunities lead to automatic reduction of errors and failures, this concerns mainly errors such as slips and mistakes. In contrast knowledge-based errors and failures require more deliberate reflection to reduce the likelihood of repeating them (Iedema et al. 2006). A study examining the effect cardiac surgeons' prior experience had on learning, demonstrated that past surgery failures improved a surgeon's future surgery outcomes (KC, Staats, \& Gino, 2013). Moreover, other cardiac surgeons' failures interacted with the surgeon's own prior failures to further improve the surgeon's surgery outcomes. In other words, one's own and others' failure experiences can have a joint effect on learning: any related failure provides an opportunity to reflect on what 
has gone wrong and how to improve procedures. Interestingly, the positive interaction effect suggest that information-based experience can have an increasing return on failure learning.

Temporal opportunities such as working conditions affect how experiences are converted into lower error rates. Residents with greater work autonomy, that is, they "perceive that they have the freedom and discretion to plan, schedule and carry out their jobs" were found to have higher error reduction (Stern et al., 2008, p. 1554). Task autonomy allowed the residents to reflect on errors and learn from them by making procedural changes. When the organizational climate was such that learning was encouraged, the residents took more time to reflect on work processes and errors and further reduced their own errors, thus, motivation (climate) and opportunity (time) interacted to accelerate learning (ibid.).

Teams play an important role in error learning (Edmondson et al. 2001); however, when the environment is ambiguous and changing, team information processing becomes complicated, which hampers learning. Individual and group levels of learning are intertwined as individual characteristics and team composition jointly determine teams' error reporting (Edmondson, 1996). Good member coordination (Baker et al. 2006) and common goals (Tjosvold, et al. 2004) enable teams to benefit from the full potential of each of their members. In the same way, team stability and work processes enable the group to better process information (Edmondson, 1996). When error information gathering activity is not a part of existing team routines (Lawton, et al. 2012), or the team does not have enough autonomy to allow it to collect critical information (Kerr, 2009), learning might not occur. In other words, having neither established nor improvised ways to gather failure information reduces opportunities to learn from failure experiences.

Group characteristics can also influence information-based learning. Group diversity and intergroup linkages are two mechanisms that provide teams with access to a wide range of information which, in turn, reduce failure rates (Chuang, et al., 2007; Tucker \& 
Edmondson, 2003). Member rotation is another way to expose teams to a greater flow of information that can enable them to better analyze problems (Argote \& Todorova, 2007). In addition, the time aspect matters here—-being exposed to many different but related experiences in a short amount of time benefits learning. Experience also transfers across levels: group-level success experience has been found to help individual-level failure learning, which ultimately benefits the learning rate of the organization as a whole (Zheng et al., 2013).

\section{Organization-level opportunity to learn from failure}

In our review of the literature, it emerged that information-based opportunity is the most studied organizational learning mechanism. To summarize across the organizational opportunity studies: experience matters in most cases and across a wide array of settings; however, it does so somewhat differently in different settings and organizations. The nature of an experience event, its outcome, rareness, and complexity, influence its learning impact. A trend in organizational-level studies is to separate one's own versus others' experiences and to focus on in which case one matters more than the other and when (Baum \& Dahlin, 2007; Chuang \& Baum, 2003; Kim \& Miner, 2007; Madsen \& Desai, 2010; Madsen, Dillon \& Tinsley, 2016).

Prior failure events provide opportunities to learn. Over time, as many problems are resolved or better managed, we would expect a diminishing return to experience, which yields a learning curve that is similar to that in production learning. In fact, there is rich empirical support that shows that learning curves have a similar shape with regard to failure reduction. Train, mining, and airline accidents have been found to reduce future accident propensity on the industry and firm levels (Baum \& Dahlin, 2007; Desai, 2016; Madsen, 2009; Haunschild \& Rhee, 2004). The failure-reducing effect is strongest for recent accidents (Haunschild, 
Polidoro \& Chandler, 2015), accidents of larger magnitude, which are measured in terms of accident cost and level of injuries (Madsen, 2009), and events of high visibility (Desai, 2011), which are measured in terms of the media scrutiny of the accidents. There are two mechanisms that can induce organizations to learn from highly visible failures: in such cases, the information about causes and remedies is more available; however, the motivation to counteract accidents may also increase when outsiders pay more attention and reputations are at stake. When there is more press attention to an accident or a product recall, organizations invest more in activities that can reduce the risk of future accidents, such as a train line installing new track (Desai, 2011).

The effect of recency, that more recent events have greater impact than older events on failure reduction, can also have multiple explanations. For instance, there is the proposition that new routines and practices make past experiences less relevant as time passes, or, as suggested by Haunschild et al. (2015), that an adverse event attracts an organization's attention and motivates the organization to reduce the risk of future accidents; however, this motivation weakens over time as other important organizational goals take precedence.

Complex problems provide a greater opportunity to learn. A notable study supporting the argument that complex challenges trigger faster and more efficient learning is an investigation of British IVF clinics, which demonstrates how opportunity affects learning (Stan \& Vermeulen, 2013). The key performance metric of IVF clinics is live births per treatment cycle, and a key aim is to lower the number of failed cycles. Whereas private clinics could choose to accept only patients with good prognoses, which meant fewer failures, public clinics were not allowed to screen patients and therefore had higher failure rates at the start of their activities. However, working with more difficult cases enhanced the information-based learning of the public clinics, and they increased their ability to successfully treat any patient, which resulted in higher learning rates than those of private clinics. Working on complex 
problems provided greater opportunity to find solutions to difficult problems and led to faster failure reduction across problems. The concept that complex failure situations provide richer information is in line with the finding that airlines learned more from complex accident causes than from simpler ones (Haunschild and Sullivan, 2002) and that this was especially true for specialist airlines. Complex problems offered more venues for learning and counteracted simplified cause-effect analyses (e.g., simplifying failure attributions to factors that are beyond the organization's control such as patient age in hospital cases or to pilot error in the case of airlines).

Whose experiences matter. Not only do failures that are experienced by an individual organization provide opportunities to learn, but the failures that are experienced by other organizations provide information for learning. Airlines learn both from their own and other airlines' accidents (Haunschild \& Sullivan, 2002). Based on the behavioral theory of firm logic, which states that organizations are more likely to look further for better solutions when their peers outperform them, train companies that had more accidents compared to their peers were found to learn more from such peers rather than from their own accidents (Baum \& Dahlin, 2007). Ontario nursing home chains learned from both their own and others' businesses with respect to naming their units. The learning effect, or willingness to change was dampened when the chain had followed a strategy for a long time (Chuang \& Baum, 2003).

Learning from near misses. It is not only failure events that provide information-based opportunities to learn, but such information can also be gleaned from events that are neither purely successful nor wholly failures (Rerup, 2006). Most attention has been given to near misses - when there is almost a failure but there are no direct negative consequences (Kessels-Habraken, et al. 2010). The opportunity to learn from near misses (especially those of others), or what is also known as latent errors (Reason, 1997; Ramanujam, 2003), is only 
possible if such actions are recorded or easily observed. Kim and Miner (2007) used the ratings of banks to capture whether they were close to failing and found that near failures affected learning more than actual failures did. Building on industry insiders' quotes, they found that near failures have greater informational content—whereas failed firms disappear from the industry and are forgotten, near failures remain and can tell their story and at the same time they also remind others of their survival. Perhaps more importantly, near failures combine bad performance with remedies for restoring performance after a period of trouble. Rather than telling a story of how to fail, they tell a story of redemption when one is close to failure. The greater informational content of the near failures means that there is a greater opportunity to learn from them. However, the reporting of near-misses and thus the information gathering process is more difficult because of the challenges in defining the scope of such events (Kessels-Habraken, et al. 2010).

\section{MOTIVATION TO LEARN FROM FAILURE}

Motivation is the desire or willingness to act in a certain way and, in the context of error and failure learning, the desire or willingness to invest in reducing adverse event frequency. Motivation to learn from failure therefore refers to the resource levels that are devoted by individuals and organizations to failure learning activity; such resources include attention and operational investments (Kanfer and Ackerman, 1989). Effective learning processes require individuals and organizations to allocate cognitive resources to (i) correctly identify and analyze error and failure causes and (ii) search for and implement solutions that prevent similar errors or failures in the future. Failure learning studies concerning motivation address contextual factors such as safety climate, psychological safety, leadership style and attitudes; cognitive and emotional barriers such as attribution errors (internal versus external); information processing in groups and, for organizational-level studies, factors that trigger 
motivation such as high visibility events and public attention. Other organization-level motivation triggers include threats to ones' reputation, social comparisons (doing worse than the competition), the recency of an event, and climate variables.

\section{Individual and group level motivation to learn from failure.}

Most individual-level studies on error and failure learning study motivational factors. In two laboratory studies, using a computer simulation task, Zhao (2011) found a positive association between participants' self-reported motivation to learn from errors and their actual failure learning. In a field study of an Australian hospital, employees' safety motivation had a positive effect on their safety participation, which was measured as behaviors that promote a safety-oriented environment (Neal \& Griffin, 2006). While individual motivation affects learning behavior in both the lab and inside organizations, organizational factors affect individual motivation to learn from failure. For example, safety climate, which is defined as "perceptions of policies, procedures, and practices related to safety" (Neal \& Griffin, 2006; 956), plays an important role in motivating individual learning. Group-level safety promotion is positively associated with individual safety motivation and safety participation in hospitals (Buljac-Samardzic et al., 2012). There are both bottom-up and top-down processes between individuals and groups that help to produce a safety climate (Neal \& Griffin, 2006). Group climate has been found to affect both individual motivation and individual behavior, and in a study of 33 organizations, individuals were more likely to report accidents when supervisors enforced safety policies (Probst, 2015). Adding the organizational level of analysis, individual attitudes to safety affects organizational learning by promoting a safety climate at the group level (Zohar \& Luria, 2005). Individual safety motivation and engagement in failure learning activities both affect and are affected by group, managerial and organizational attitudes. 
Motivation to learn from failure is also driven by individuals' causal attributions concerning failures. In attribution theory, individuals cope with outcomes by making causal attributions to guide their future behaviors (Ilgen and Davis, 2000; Nisbett and Ross, 1980). Causal attribution involves how an individual allocates causes for a certain outcome, which, in turn, influence his or her motivation to learn. Specifically, individuals tend to attribute success to internal causes such as ability and effort, and failure to external causes such as environmental factors and luck (cf. Jones \& Harris, 1967). At the same time, individuals often turn this around and attribute others' successes to external causes and others' failures to internal causes. Such attributions affect individual motivation to engage in failure learning activity (Chuang et al., 2007; Zhao and Olivera, 2006). Attribution theory helps us to better understand the previously discussed result that surgeons' cumulative number of successful cardiac procedures had a greater impact on their future success rate than failed procedures had, while other surgeons' cumulative number of failed procedures significantly helped to improve a cardiac surgeon's subsequent success rate (KC et al., 2013). One can argue that surgeons attributed the prior successes to their own effort and actions, while the prior failures were attributed to uncontrollable factors. Thus, the surgeons assumed that there was little to learn from own failed procedures. In contrast, other surgeons' failures were attributed to their efforts and actions, which made the focal surgeon more willing to review and learn from others' failure causes. In a similar vein, individuals who work in teams attributed failure to actions that are taken by other individual team members rather than by the team when they experience poor team performance in a laboratory setting (Naquin and Tynan, 2003).

However, this tendency decreased as subjects' knowledge of teamwork increased. Another sign that attribution biases can be alleviated is a study in which individuals were better able to make internal attributions after failing in a task when they received after-event reviews that helped them to understand what contributed to their performance (Ellis, Mendel, and Nir, 
2006). Individuals who made more internal than external attributions improved their performance more. In a study of CEO attributions and organizational performance, Salancik and Meindl (1984) found an even stronger learning effect from internal attributions: when CEOs attributed poor firm performance to internal causes even when the low performance was clearly caused by an external factor, their firms performed better in subsequent periods. Internal attributions are clearly important for behavioral change.

Failures often generate strong negative emotions (Paget, 1988) as individuals experience feelings of guilt, embarrassment or fear when they are involved in failures or make errors (Edmondson, 1996; Paget, 1988). Negative emotions prompt individuals to become more risk averse (Loewenstein et al., 2001), affect judgment (Forgas, 1995), and lower engagement in failure learning. In general, failure-induced negative emotions should lower individuals' motivation to learn. However, in a laboratory study, negative emotions were instead positively associated with the motivation to learn (Zhao, 2011). The author explains this effect by suggesting that the strength of emotions matters, not just whether an emotion is negative, and negative emotion only affects learning above a relatively high threshold. If the strength of emotion matters, the finding that managerial error intolerance increases negative emotions suggests that managers' attitudes can push staff into non-learning (Keith \& Frese, 2005).

There are individual differences in the emotional response to failure and individual differences in coping orientations that help to explain the different emotions that are generated by failure as well as differences in the motivation to learn from failure: Individual affective organizational commitment - how loyal they feel towards their organizationsdecreased with negative emotions about failure (Shepherd et al., 2011); however, this link between negative emotions and failure was moderated by coping orientations when dealing 
with failure. Negative emotions also decrease when individuals perceive that failure is a normal occurrence in their work environment (Shepherd et al. 2011).

Individuals' motivation to learn from failure is affected by psychological safety. Not to be confused with safety climate, psychological safety refers to the perception that it is safe to take interpersonal and professional risks in the workplace (Edmonson, 1999; Edmonson and Lei, 2014). Psychological safety has been found to positively influence failure learning by increasing an individual's motivation to engage in failure learning activity (reporting failures and errors; willingness to discuss possible solutions) because the fear of negative consequences to self-image, status, or career are lower when psychological safety is high (Edmondson, 1996; Tjosvold, et al. 2004). Surveying three firms in the software, electronics and finance industries, Carmeli and Gittell (2009) found that psychological safety was positively associated with failure-based learning behaviors.

At the group level, group norms shape learning from failure: compliance with norms motivates individuals to identify and record failures and to act to prevent them (e.g., KatzNavon et al., 2009; Vogus \& Sutcliffe, 2007; Zohar, 2002). When studying groups in different functions in the same organization, sharing the same beliefs about how to cope with failure exerted great influence on failure learning (Cannon \& Edmondson, 2001).

Information sharing and interpersonal relationships within groups is another key element impacting how motivated teams' are to learn from failures. Teams with cooperative rather than competitive goals learn more (Tjosvold, et al. 2004). Trust between the members of a team affects learning motivation (Carmeli et al. 2012). Comparing hospitals with similar characteristics but different failure learning rates, Edmondson et al., (2001) found that team member error information sharing affected the learning rate. In a similar fashion, managerial safety practices also affect the motivation to learn - managers who demonstrate that safety is important positively affect error reduction (Katz-Navon et al. 2009). Lack of information 
sharing depends on the routines, awareness of others' knowledge and status dynamics within groups: a study found that slower-learning groups had team members that did not bring attention to errors since they assumed, often incorrectly, that other team members are already aware of them (Cannon \& Edmondson, 2001; Edmondson, et al. 2001).

According to Gersick \& Hackman (1990), routines are double-edged swords: on the one hand, they can prevent team members from addressing failure by reducing their motivation to learn because change would upset the routine; however, on the other hand, routines create comfort within a group and lead to a climate where group members are more comfortable sharing what went wrong.

A high team workload not only decreases the opportunity to learn, it also considerably reduces team motivation to learn from failure (Lawton et al. 2012), and it may ultimately affect the ability to change because the team might be unaware of the need to improve existing routines (Edmonton, et al. 2001). Team's ability to manage its workload is also important, and teams that do better at his were found to improve their error rate faster (Lawton, et al. 2012). To reduce errors and failures routines often need replacing, but renewing routines is cumbersome, with preexisting routines being obstacles to change; thus, unless there is a clear rationale for why routines must change, groups are likely to resist change and may even implement defensive strategies with respect to learning processes, for example, by shifting responsibility and finding arguments to defend failing mechanisms (Hodgkinson \& Wright, 2002). Workload is a time-dependent opportunity but also impacts motivation to learn since decisions that are made under time pressure may require individuals and groups to focus on a shorter-term horizon (Malone et al. 2007).

\section{Organization-level motivation to learn from failure.}


A majority of the studies on how motivation affects error and failure are conducted in the health care context. There is a very real concern that hospitals are not reducing their error rates and are causing patient harm at a high rate (Leape, 1994; Kohn et al., 2000). The focus is often on how individual motivation to report errors is affected by organizational factors. The problem of non-reporting is high (Zhaou \& Olivera, 2006; Ramanujam, 2003), which renders the analysis of error causes incomplete. The reason for an individual to not report an error that he or she made, or which was made by someone close, is often a lack of trust that responsible managers in the organization will conduct proper analyses to determine the true causes. It is a common and simple solution for organizations to blame an error on an individual (Hofmann \& Stetzer, 1998; Rathert \& May, 2007). The belief that organizations prefer to blame individuals rather than to find organizational causes is supported by data: Perrow (1999) reported that a re-examination of industrial accident causes where $70 \%$ to $80 \%$ were attributed to operator errors, in contrast found that operators had caused less than half of the accidents they were blamed for, or that $30 \%$ to $40 \%$ of accidents were caused by operator errors.

In line with the tendency to blame the person who is closest to an error, factors that impede error reporting and analysis at the organizational level can be linked to the culture of blaming individuals rather than exploring other error causes (Khatri et al., 2009), ward climate (Lawton et al. 2012), whether health care work units are patient-centered (work is planned around the patient's needs) (Rathert \& May, 2007) and that when greater distance between professional groups in health care reduces the willingness of orderlies and nurses to admit to or discuss errors with doctors (Khatri et al., 2009). Organizational climate is a determinant that trickles down to affect both group and individual-level learning from failure.

Motivational factors that have been studied outside health care are different. Based on the behavioral theory of firms, which states that organizations are more motivated to act and 
change when they perform worse than they did in the past or when they perform worse than their competitors or peers (Cyert \& March, 1963), Baum and Dahlin (2007) found that train companies that have higher accident costs than their peers learn faster but mainly from others' experiences. Learning from others' and not one's own experiences might be due to poor failure performance: the organization might need external ideas of how to change behaviors. Another motivation study found that when an automobile manufacturer were forced to recall products and thus its reputation was challenged, the likelihood of future recalls was lowered (Haunschild \& Rhee, 2004; Rhee, 2009). The effect in the auto recall case was curvilinear: low- and high-reputation car companies reduced recalls less than companies with medium reputations did. In a study that focused on how motivations change over time, Haunschild et al. (2015) found that a recent failure (in their case, a pharmaceutical product recall) made the organization work to reduce future such events; however, as time passed, other performance metrics, such as profits, reclaimed the organization's attention and lowered the focus on failure reduction.

Some findings on how attention impacts motivation contradict one another. While more media coverage after an accident motivates greater investment in infrastructure for train companies, thus reducing accident risks (Desai, 2011); more media coverage of the nearmisses involving air traffic controllers instead reduced the effect of prior near-misses on learning (Desai, 2014). This divergence could be explained by near- misses looking alarming to outsiders since an actual failure (airline accident) would have catastrophic consequences, while organizational members, in contrast, see a near-miss as a success since an error was rectified and a failure was avoided (Kessels-Habraken, et al. 2010; Dillon \& Tinsley, 2008) .

\section{ABILITY TO LEARN FROM FAILURE}


Ability to learn from failure concerns the capacity to identify and report failure;

understanding failure leads to finding and implementing solutions to prevent future failures. Individual and group level studies are concerned with training, emotional responses, shared goals and managerial style, as well as the interaction between ability and motivation. Organization-level studies rarely measure directly ability but rather conclude that the unobservable variances across units or organizations are due to differences in ability. In health care, where geography makes competition between hospitals less of an issue, checklists are used for the transfer of best practices across units, which raises the ability to learn in organizations.

\section{Individual- and group-level ability to learn from failure}

The question of how to improve individuals' ability to learn from their errors and failure experiences has led to a series of studies that focus on comparing different training methods and the role of post-event reviews. Keith and Frese (2005) compared error management training, which explicitly addresses individuals who make errors during training and uses these errors as learning exercises and error avoidance training, which instead focuses on preventing participants from making errors. Error management training enhanced individuals' capacity to cope with, and generate solutions to, new problems. Error management training also led to better emotion control and metacognitive activity, which in turn improved individuals' ability to cope with new problems. Individual differences interact with training method so that individuals with better cognitive ability and higher openness to experience were found to perform better during error management training than if they had received no training or only training with a focus on error avoidance situations. Error management training not only provides trainees with opportunities to make errors but also to receive informative feedback; overall, these programs increase an individual's ability to learn from 
failure. Thus, the ability to learn from failure can be actively developed, and such training is more effective when it is paired with high motivation to learn from failure (Katz-Navon, et al. 2005).

A laboratory study on how to enhance individuals' ability to draw lessons from previous experiences found that after-event reviews of both successful and failed events had a positive impact on individual learning (Ellis and Davidi, 2005). The after-event reviews followed a similar but more extensive process than that of error management training because it also included successful events. While the participants' mental models of failure events were richer than those of success events, the performance improvements were greater when the after-event reviews focused on both failures and successes. In a follow-up study, any type of after-event review (success, failure or both types of events) was found to lead to better performance compared with no after-event review. Interestingly, for individuals who experienced successful events, the after-event reviews that focused on the failure factors that led to the greatest performance improvements had a greater impact than no reviews, reviews that focused on success factors, or on both success and failure factors (Ellis et al., 2006). Individual differences in how failure is processed has an impact on failure learning. Studying three types of coping orientations: loss, restoration, and oscillation, Shepherd and colleagues (2011) analyzed how these orientations affected (self-reported) learning. Loss orientation refers to the explicitly processing of a failure to break the emotion that is associated with the failure (a failed project). Restoration orientation refers to suppressing feelings of loss and instead proactively focusing on the tasks that arise as a consequence of the failure rather than preventing future failures. An oscillation orientation refers to moving back and forth between loss and restoration orientations. Individuals who have stronger loss and oscillation orientations reported a better ability to learn from previous project failure than those with a restoration orientation. Apparently, the necessary element is the capacity to 
emotionally disconnect from the failure, which suggests that effective learning involves managing the emotions that are evoked by a failure.

An individual's ability and motivation to learn from failures are affected by emotional states. The ability to learn is enhanced when the environment is emotionally supportive: Individuals must feel comfortable applying their knowledge and acquiring new knowledge to learn from failures. An individual's perception of psychological safety and the quality of his or her relationships with others in an organization are positively associated with failure learning (Carmeli and Gittell, 2009). High-quality relationships, which are manifested in shared goals, shared knowledge, and mutual respect, not only promote psychological safety but also enhance information processing and coordination capacity, which in turn have positive effects on the capacity to learn from failure.

Individuals can also encourage failure learning at the group level with a positive leadership style, which includes clear direction and effective coaching (Cannon \& Edmondson, 2001; Katz-Navon et al., 2009): leadership style can motivate learning; however, it also reflects the group's ability to learn and a leader's ability to enhance group learning. For example, when a CEO fosters psychological trust in a top management team (between the $\mathrm{CEO}$ and the team, and within the team), the team is more likely to engage in failure learning and to produce high quality strategic decisions (Carmeli, et al. 2012).

Because individuals in organizations are embedded in groups, studies have stressed teamwork to be an important factor for failure learning (Baker, et al. 2006; Morey, et al. 2002). Many studies of ability involve overlapping and interactive effects between motivation and ability, and some determinants are related to both mechanisms. Efficient teamwork relies on coordination and communication, which can be actively promoted (Baker et al. 2006) using formal training to improve team collaboration (Morey et al. 2002). Ability to foster cooperative goals also triggers failure learning (Tjosvold, et al. 2004). Most ability-type 
factors can be taught, and they can, in turn, nurture group motivation to learn. Other grouplevel factors that improve group learning ability are group member stability, understanding of team processes, and training to reduce attribution biases (Buljac-Samardzic, van Woerkom, \& Paauwe, 2012; Morey, et al, 2002; Naquin \& Tynan, 2003).

A process study of of how ability is developed focuses on Israeli fighter crews (Ron, Lippschitz \& Popper, 2006). To reduce errors in flight procedures, crews not only relied on their own learning based on flying more missions and thus learning through direct observation and experience; rather, because they knew that subjective perceptions are incomplete and sometimes faulty, given the intensity and massive information processing that is required when piloting a fighter jet, after each mission the entire cadre held a debriefing. In the debriefing crews watched footage from aircraft cameras while talking through their perceptions of what had occurred. The review process allowed them to compare their perceptions with the footage, clearly see how imprecise real-time perceptions are, which helped them to make corrections, and convert subjective experiences to objective ones. The review process and the debriefing are imposed by the organization, it enhanced the teams' abilities and also increased information-based opportunities since the debriefing sessions provided the crews with additional information.

\section{Organization-level ability to learn from failure}

We found fewer studies on organizational-level ability than on organizational-level opportunity or motivation. A study analyzing failure reduction across clinics that use a new heart surgery method used an indirect measure of clinic ability (Pisano et al., 2001). Carefully establishing that given the same opportunity (cumulative number of procedures, which had a large impact on learning) and motivation, organizations differed in how well they converted experience into higher performance: the 16 clinics in the study demonstrated different 
learning curve slopes. After ruling out other opportunity-based explanations, the conclusion was that differences across clinics must be due to (unobserved) ability. A paper argues that organizational form, whether an airline is a specialist or generalist, can influence its ability to learn from failure (Haunschild and Sullivan, 2002). Generalists have a more complex organizational structure with the potential to complicate information processing and coordination, which in turn hampers learning. In the airline industry specialists compared to generalists were better able to learn from failures with heterogeneous, that is, more complex causes. Similarly, smaller hospitals (more specialized), compared to large hospitals (more generalists), have been found to engage in more learning behaviors related to major adverse events and near-misses (Ginsburg et al, 2010).

More detailed measures of ability demonstrate that ability affects the absolute number of errors as well as the reduction of errors: hospitals achieve faster learning and fewer errors by implementing protocols and checklists developed from best practices across the industry (WHO, 2017; Thornlow \& Merwin, 2009; Thomassen et al., 2-13). Checklists were originally introduced in aviation, where they have been partly credited with the rapid decline in accidents (Clay-Williams \& Colligan, 2015). Hospitals with patient-centered units were better at processing and reporting errors and near misses, which suggests that the organization of work matters for an organization's ability to manage failures (Rathert \& May, 2007).

\section{SYNTHESIS ACROSS LEVELS OF ANALYSIS}

A large body of literature finds that individuals, groups and organizations learn from prior failure experience. Information opportunities positively affect learning rate. The richer the information, the faster the reduction in errors and failure. Failure experiences generally contain more information than successful experiences (Kim \& Miner, 2007). Most successes are "business as usual" contributing to learning by doing and other automatic responses, thus 
enforcing existing routines. In contrast, failures trigger analyses and have greater potential to improve routines (Stan \& Vermuelen, 2013). A lack of routines for error and failure management stops the information from passing through an organization (Gersick \& Hackman, 1990; Kim \& Miner, 2007). Larger-magnitude, more frequent and salient errors have greater information content and, hence, learning opportunities (Baum \& Dahlin, 2007; Chuang \& Baum, 2003; Madsen, 2009; Desai, 2011). Near misses also provide information about how to recover from a bad situation, which increases opportunities to learn (Kim \& Miner, 2007). In general, studies find that "more is better" in regard to information-based learning opportunities; however, we would expect an overload when failures and errors are too frequent (Dahlin \& Roulet, 2014). Information overload that leads to limited failure learning can hamper the ability to learn from failure. Accepting frequent errors due to information overload, that is, not learning from them, can also be a sign of low motivation to learn. These two factors — low ability and low motivation to learn—may be difficult to distinguish (Baum \& Dahlin, 2007; Dahlin \& Roulet, 2014).

Time-based, or temporal, learning opportunities operate in the same direction and in a similar fashion as information-based learning opportunities: a lower work load leads to fewer errors and failures since work load reduces the time that is available for learning (Malone et al. 2007; Lawton, et al. 2012). Nevertheless, some groups are able to analyze and process information faster, taking advantage of temporal learning opportunities to enhance their future performance (Edmondson, et al. 2001). Whether temporal opportunities can trigger learning also depends on whether individuals in organizations have autonomy to process and reflect on the errors and failures that they encounter (Kerr, 2009; Stern, et al., 2008). To that end, organizational design (e.g., workload, task autonomy) has the potential to lead to latent failure that hampers learning opportunities. 
Even when opportunity to learn from failure - whether information- or time-based — is high, learning may not occur. While opportunity studies are more concerned with what enables learning, motivation studies focus on why learning does not happen. Conditions under which individuals attribute the causes of errors and failures to other factors, groups attribute the causes of errors and failures to factors other than the group collective, and organizations attribute the causes of errors and failures to individuals rather than organizational factors, reduce the motivation to learn, which leads to low error and failure reporting and lower learning rates (Chuang et al., 2007; Ellis et al., 2006; KC, Staats \& Gino, 2013). A costbenefit model that is proposed by Zhou and Olivera (2006) offers an overarching explanation to this problem: the unbiased reporting of errors is only expected when the perceived reporting cost is low to both an individual and his or her organization, and the perceived benefits for reporting is high to both as well as to any victim(s) who are associated with the errors. All other combinations of costs and benefits distort the motivation to report and what will be reported, which in turn affects the opportunity to learn from failure. In empirical studies, climate or psychological safety can be thought of as a reporting cost. Patient-centered climate (Rathert \& May, 2007), low hierarchical distance, non-blaming cultures (Kathri et al. 2009) and high psychological safety (Tjosvold et al. 2004) lead to better reporting and learning. The perception of the benefits to reporting are affected by the same factors; however, this side of the explanation for failure learning is less investigated.

On the organizational level, conflicting goals, often safety and profitability, affect the motivation to learn from failure: A recent failure highlights safety goals for employees; however, as time passes, the focus reverts to financial performance metrics (Haunschild et al., 2015). This highlights the risk of taking failure reduction for granted, assuming that learning is irreversible. Unless learning is embedded in physical artifacts (better brakes, a new IT 
trading system) or it becomes a part of organizational routine, there is always the risk that error and failure rates will reverse.

Ability studies show that training programs and after-event analyses can improve individual and group abilities to correctly analyze situations (Keith \& Frese, 2005). It is clear that such training is quite common, with checklists being used in different industries, such as aviation and health care, to enhance organizational safety work (Clay-Williams \& Colligan, 2015).

\section{Integration across mechanisms}

Most studies focus on one or (at most) two mechanisms, either opportunity, motivation or ability, and we know that they all matter for failure learning. We know less about how the mechanisms affect one another. While some studies have considered moderating effects (KC, et al., 2013; Madsen \& Desai, 2010; Shepherd at al., 2011), mediation is more seldom mentioned. If opportunity to learn sets the stage (providing information for failure analysis that can improve routines and failure responses), motivation causes actors to be willing to attend to such information, and ability is the conversion of opportunity into higher performance. What we do not clearly know is how, and whether, these three mechanisms jointly affect failure learning.

Theoretical arguments about how to combine the different mechanisms argue for a three-way interaction (Blumberg \& Pringle, 1982; Reinholt et al., 2011). However, it may just as well be a moderation-mediation process where the opportunity to learn interacts with the motivation to learn, and such interaction is mediated by the ability to learn, which results in failure learning. The empirical research focuses on one or two of the mechanisms, at most testing two-way interactions (for instance, how ability and motivation jointly determine learning). The notion that reality is complex is illuminated by different findings, some of 
which find interactions between factors, others of which find that one factor affects learning but is mediated by a second factor. Motivation is thus found to affect ability, but ability also affects motivation (Lawton et al., 2012; Hofman \& Stetzer, 1998) with both paths leading to learning. Further, motivation and opportunity jointly lead to learning (Haunschild et al. 2015), opportunity affects ability, which leads to learning (Stan \& Vermuelen, 2013) and opportunity and motivation interact to produce learning (Baum \& Dahlin, 2007). It is clear that the interplay between the mechanisms is more complex than we originally thought, and this promises many different ways to stimulate failure learning.

\section{MOVING BEYOND THE THREE FAILURE LEARNING MECHANISMS}

The papers in the review section covered both error and failure reduction. While there are many similarities between them, errors and failures are different types of events (Zhao \& Olivera, 2006). Errors are mistakes, slips or violations of procedures, and they might or might not lead to an adverse outcome (Rasmusen, 1982; Reason, 1990). Failures are adverse outcomes ${ }^{3}$, such as accidents, unexpected patient deaths or bankruptcies (Tucker \& Edmondson, 2003). While reducing errors should reduce failures, in this section we will discuss how these two types of events have a complex relationship; through a better understanding of this relationship, we can also better understand the differences in learning rates.

\section{Differentiating process and outcomes}

When we study failures, that is, adverse outcomes such as product recalls, accidents, bankruptcies or unexpected hospital deaths, we assume that the cause of an adverse outcome is an erroneous process. Correspondingly, when we study traditional learning with successful outcomes, we assume that processes that lead up to the outcomes are correctly executed.

\footnotetext{
${ }^{3}$ We use the terms adverse outcomes, failures and undesirable outcomes interchangeably.
} 
Questioning the strong link between the correctness of processes and outcomes, there is an increasing interest in situations in which erroneous processes can still result in good outcomes, such as near-misses (cf. Kim \& Miner, 2007) and latent errors (Ramanujam, 2003; Reason, 1990). It is also possible, but rarely discussed, that a correct process can lead to an adverse outcome, such as a patient dying, even after well-executed surgery ${ }^{4}$. We propose that to better understand failure learning we must decouple processes and outcomes, or, more precisely, independently assess whether a process is correctly performed and whether an outcome is desirable. We also argue that different settings have different frequency distributions for the process-outcome pairs and that opportunity, ability and motivation to learn from failures (and successes) depend on this distribution, which explains why lessons in failure learning in one setting can be difficult to translate to another.

If we regard processes as either correct or erroneous, and outcomes as successes or failures, we end up with four possible process-outcome combinations (see Table 2).

\section{TABLE 2 TO BE INSERTED HERE}

\section{Success and failure learning. A correct process with a favorable outcome represents} traditional learning in which the outcome motivates actors who continuously improve and/or exploit the process to further enhance the outcome. This is what we expect from production learning curves (box 1 in Table 2). A faulty process with an undesirable outcome represents the "normal" failure learning case — an error is made, which yields a bad result (a train driver falls asleep, ignores a signal, and collides with another train; box 4). The main thrust in success learning is on how to improve existing processes to enhance the number of successful operations per time unit and thus lower the cost per unit produced (Argote, 2012; Yelle,

\footnotetext{
${ }^{4}$ Over time the number of different health interventions has greatly increased, many of which have been directed towards terminally ill patients (Maile, 2012).
} 
1979). The main thrust in failure learning is the analysis of how to improve the processes, reduce errors, and thereby lower the risk of failure or reduce the number of failed operations per time unit (or as a share of all operations) (Reason, 1997).

The assumption is that box 4 is a good representation of failure situations: if there is a failure outcome, there must be a preceding error. As a consequence, failures should be reduced when errors are reduced, and this approach of error reduction lies behind much successful failure reduction (Reason, 1997; Van Dyck et al. 2005). Similarly, the assumption is that successful outcomes are due to an error-free process. However, there are two other possibilities in the matrix that complicate learning: the off-diagonal combinations where (1) an error has no effect on the outcome, that is, does not lead to a failure (Ramanujam, 2003), or (2) when there is a failure outcome without an error that has been committed (e.g., an "act of God"). The very existence of the off-diagonal combinations weakens the link between a process as being either correct and not, and its outcome as being either successful or not. We label the off-diagonal combinations spurious successes and spurious failures. An increase in spurious events leads to noisier learning processes because the cause-effect analysis becomes more complex, which in turn introduces difficulty in learning from both successes and failures. We expect that both spurious successes and failures complicate learning in general and failure learning in particular. Spurious successes and failures are likely to shift the attention of individuals and organizations away from the "true" causal-effects of failure, making failure learning challenging. Because successes tend to be vastly more common than failures, ${ }^{5}$ we failure learning should be more sensitive to the occurrence of spurious events.

Spurious success. Not all errors lead to bad outcomes. We expect that both the motivation and ability to learn from an erroneous process is lower when an organization experiences a spurious success, that is, there is no negative outcome (Table 2, box 3). Further 
lowering learning ability, many process errors are unreported (and sometimes also

unobserved) and unreported errors are known as latent errors (cf. Ramanujam, 2013; Reason, 1997). Latent errors can lower failure reduction because a near-failure without an adverse outcome can strengthen an erroneous behavior.. The lower the likelihood that an error will lead to a failure, the more the error is accepted and the lower the motivation to correct the error or to learn from it is (Dillon \& Tinsley, 2008; Banja, 2010). The motivation to reduce errors is also compromised because risk perception changes when actors experience errors without negative effects (a train driver falls asleep but wakes up before missing the signal, or, if the driver misses the signal, no other train is on the line, thus, there is no collision - the conclusion is that being tired on the job is not such a dangerous thing). Japanese nuclear firms did not learn from other firms' errors without adverse outcomes when these errors were similar to non-adverse outcome errors the focal firm had experienced itself (Mitsuhashi, 2012). This suggests that spurious success also lowers the motivation to learn from others' errors: Knowing that other firms in the industry experience similar errors without adverse consequences signals that these errors pose no real risk and thus require little attention. When latent errors start being accepted by organizational members as not leading to adverse events, we obtain what is called normalization of deviance (Banja, 2010; Vaughan, 1996).

Normalization of deviance involves accepting errors and rule breaking. Deliberate rule breaking is usually a dismissal of rules that are considered to be ill-conceived or overly complex. It is a gradual process (Vaughan, 1996) and in the majority of cases, normalized deviance has no negative outcome.

Normalized deviance is often exposed after a dramatic failure event leads to patient death (Maxfield, Grenny, Patterson, McMillan, \& Switzler, 2005), nuclear meltdown (Dekker, 2011), spectacular trading losses (The Economist, 2014) or the crash of a space shuttle (Vaughan, 1996). Normalized deviance means that there is an implicit or explicit 
agreement among organizational members to ignore certain safety procedures or regulations. One effect of normalized deviance is that it complicates cause-effect analyses when a failure strikes: it is easy for analysis to focus on the deviance behavior, which might not be the main cause of the failure. After all, some procedures or regulations are probably outdated or ineffectual and ignored for good reasons. In health care, normalized deviance often involves the violation of safety rules that impede work flow and signal a lack of trust in operators (Banja, 2010). Normalized deviance can also come from institutional logics that became dominant over time inside an industry despite their clashing with broader order values and beliefs that lie outside of the industry (Roulet, 2015; Shymko \& Roulet, 2017).

Despite a weak link between latent errors and failure outcomes (cf. Dekker, 2011), some settings still exhibit strong learning under such circumstances (airline safety, automobile safety), and it would enhance learning if we can determine factors that trigger learning from latent errors. First, the human error and safety literature is focused on errors regardless of outcomes, with a clear acceptance that adverse outcomes are quite infrequent; however, despite the low probability of an error that leads to a failure, there is nevertheless a link (Reason, 1997). When the focus is on errors rather than outcomes, both motivation and ability to learn should be enhanced. Creating agencies whose mission is error detection and reduction, such as the NTSB in transportation, leads to a low tolerance for errors. Some agencies have the power to close down or fine error-prone organizations with the aim of limiting such trade-offs in organizations, thus enhancing the organizations' motivation to engage in failure reduction. Organizations' and their members' ability to reduce errors is also improved as regulators help with cause-effect analyses and recommend or regulate safer behaviors (FRA, 2016).

Spurious failures. The fourth process-outcome combination is the case where a faultless process produces an adverse outcome (Table 2, box 4). For instance, well-executed surgery 
can still lead to a patient dying, or correct driver behavior can produce an accident. We call this a spurious failure, and this particular outcome is problematic for failure learning for a number of reasons. A failure outcome often triggers a search for causes even if there is none. Such a search risks misattributing the process as faulty, and there is a risk that the organization will replace a good routine with a worse one or make inefficient changes, and thus the ability to learn is compromised. The good-process-bad-outcome option is fairly rarely studied; however, it is likely to be frequent in complex settings where many processes cooccur and involve many different actors. Because organizations are twice as likely as an impartial observer to assign blame to an operator after a failed event (Perrow, 1999), spurious failures are risky for individuals who might be unfairly blamed for adverse outcomes when the organization looks for failure causes. Thus, spurious failures can lead to lower trust and lower reporting of actual errors, which lowers the motivation to learn (Hofmann \& Stetzer, 1998).

Health care is an obvious case where we expect frequent spurious failures because very sick patients eventually tend to die regardless of treatment. Staff is acutely aware that many failures (such as death) occur for reasons that are unrelated to any procedures that they perform, and this leads them to accept bad outcomes as an unavoidable part of everyday activities. While the acceptance of adverse outcomes is necessary, there is a risk of acceptance spilling over and allowing errors and latent errors to be forgiven: Because death is an expected and even unavoidable outcome for many patients, even when the cause of death is an error instead of an underlying disease and the outcome should be recorded as a failure, the high incidence of spurious failures might mean that errors are not detected. In addition, even if an error is detected, it might be ignored and therefore not corrected (Kohn, Corrigan \& Donaldson, 2000). In other words, normalized deviance can be affected by spurious failures as well as by spurious successes. 
In summary, the more frequent spurious learning and failure, or bad-good combinations, there are (boxes 2 and 3), the more difficult it is to perform a correct causal analysis. The combination of process error - good outcome is probably more common than that of the process error-bad outcome. An analysis of airline crews found that an error was made in the cockpit during a flight at least every four minutes but that very few incidents or accidents resulted (Bird, 1969; Reason, 1997). Similarly, nurses commit errors once every hour; however, this rarely leads to bad outcomes (Tucker \& Spear, 2006). In contrast, we have almost no information about how often a correct process results in an adverse outcome. Learning motivation is low when the off-diagonal events are frequent, as is the opportunity to learn given the noisy information.

When there are many processes that can simultaneously go wrong, attending to all potential errors becomes cumbersome and this also makes cause-effect analyses difficult. Simulations are well suited to investigating these trade-offs as well as experimenting with the complexity of tasks, the number of involved parties, risk levels and how these factors affect motivation and ability to learn (cf. Denrell, 2003).

\section{The impact of spurious successes and spurious failures on slow- and fast-learning settings}

Noise and uncertainty in the process-outcome relationship help to explain learning-rate differences across settings. In settings with more off-diagonal outcomes (boxes 2 and 3), we expect lower learning rates since both ability and motivation to learn are lowered, and causal inferences are more difficult to draw. Spurious success (box 3), for example, is more likely to occur in situations in which tasks are easy and the rate of success is naturally high, while spurious failures (box 2) will, by contrast, be more common when tasks are complex, the chance of making an error is high and the risk of failure is also high. In the health care sector, 
relatively routine procedures would be expected to lead to a higher rate of spurious success. By comparison, complex and high-risk surgical operations are more likely to lead to spurious failures. Those contexts offer fewer opportunities to learn because there is less information on which to draw for further success. The learning process is also hampered by the difficulty in assessing and taking stock of ability: the more spurious failures there are, the greater the doubt about current abilities will be. We also expect that motivation to learn will be lower in settings with high rates of spurious failure and success given the ambiguity with regard to cause and effect.

\section{FUTURE RESEARCH DIRECTIONS}

How can organizations best learn from errors and failures? We will suggest a number of approaches that are based on the ideas of maximizing the triad of learning mechanisms, opportunity, ability and motivation while taking into account the role of spurious failures and spurious successes.

\section{Opportunity to learn from failure}

Using multiple sources of event information and the role of regulations. What can organizations do when they experience few failures but still want to reduce future failure risk? There is an increasing emphasis in learning studies on vicarious learning in the form of organizations' learning from similar others' failures, successes and near-miss experiences (Baum \& Dahlin, 2007; Haunschild \& Sullivan, 2002; Kim \& Miner, 2007; Madsen \& Desai, 2010), and thus one way to increase learning opportunities is to learn from others. Moreover, information about events is also provided by an array of industry stakeholders such as the press, unions, regulators, industry associations, insurance companies, equipment manufacturers, trade press and academics. All of these groups have an interest in failure 
reduction, and some are mandated to collect data, investigate accidents and issue recommendations. They provide information, analysis and suggestions on how to reduce failures, and some of them are very active. However, management scholars have mostly ignored these stakeholders and the role that they play in identifying, analyzing and suggesting remedies for failures. As a consequence, there is an omitted variable bias in many studies, which overestimate the effect of one's own or others' ability to learn from failures (Dahlin \& Roulet, 2014). In addition, it would be interesting to examine the relative impact of different learning sources on failure learning to better understand stakeholder roles. We call for future studies in management to include more industry stakeholders, or at least to control for their actions to better understand the sources of learning. While policy studies are engaging with this question to study the effect on an entire industry (Silbey, 2009; Dekker, 2011) they rarely analyze firm-level factors.

Some key questions to ask when investigating the role of multiple parties are: Given different learning rates across industries: are there fewer sources of learning in slow-learning settings? Can a slower learning rate be explained by a lower opportunity to learn?

Noise also lowers opportunity to learn: If slow-learning settings are more likely to combine a high failure volume and a high spurious failure volume, is it possible that lower failure learning rates are due to the difficulty to learn from spurious failures? Spurious failures create a great deal of noise, which makes cause-effect analyses complicated and makes more common failure cases (erroneous process - adverse outcome) difficult to analyze. Exploring these questions can further advance our understanding of the differences in failure learning across settings.

Opportunity and the transfer of learning. One way to transfer best practices developed in a high-performing organization or industry to a lower-performing organization or industry is to use checklists (Degani \& Wiener, 1993; Thomassen, Storesund, Søfteland, \& Brattebø, 2014). 
Checklists are required in aviation and their success has led to their adoption in health care.

They are, for example, increasingly used in surgical procedures. Checklists have been effective in accelerating learning, with more rapid failure reductions in units that use surgery checklists than in units that do not use surgery checklists (Walker, Reshamwalla \& Wilson, 2012). However, in a meta-analysis of checklist studies, Thomassen et al. (2014) reported either improvement or no effects in the use of checklists. When some non-learning situations were more closely analyzed it was found that the checklists were not properly implementedsome surgeons have resisted their use (Leape, 2014).

Checklists are also used for data collection and analysis by US transportation safety agencies, such as the National Transportation Safety Board when they investigate accidents and has helped to reduce airline and train accidents (NTSB, 1998). Since the transportation sector is heavily regulated, all agencies are tasked with safety interventions and trained in using systematic tools while it is not clear if enforced checklists use by external agencies would be as effective in the health care setting. Maybe health care is too complex (different professional groups, hierarchical structures that complicate communication between groups, a large number of diagnostic and treatment options, complex information flow), thus requiring different tools to facilitate failure learning beyond learning on the procedural level? At the same time there are few other tools to facilitate information transfer that have been as extensively developed and whose impact is as well understood as the learning effects of checklists (Leape, 2014). We wonder what other methods and/or tools could be used to increase learning opportunities in general and which methods and/or tools might be effective for slow-learning environments in particular.

\section{Ability to learn from failure}


1

2

3

4

5

8

10

Ability is the learning mechanism that is most difficult to investigate, and we find a large gap in our understanding of how to improve ability. While there are case studies that conclude that failure learning is difficult, with many factors that are used to explain when learning will not occur (cf. Baumard \& Starbuck, 2005), there are fewer studies that explain high learning rates (i.e., a better ability to learn from failure).

Can ability to learn from failure be improved? After-event analysis and error management are ways to improve failure learning. Our review revealed that psychological safety and nonhierarchical environments with good communication and coordination within and between teams also lead to more learning from errors and failures. This result then begs the question for organizations that lack good communication and have low psychological safety: how can they increase their failure learning ability? Can psychological safety be promoted by the same manager who pushes the norms of non-reporting? What types of action are necessary for organizations that wish to adopt the climate and norms of more successful failure learning organizations? Conversely, in organizations with good managerial support for error reporting and psychological safety, how can learning ability be further enhanced? 


\section{How much of learning is automatic? How does ability evolve? Some performance}

improvements in the learning-curve literature are virtually automatic; learning-by-doing is played out at the individual level (Thompson, 2012), and learning-by-doing implies that individuals' abilities increase by themselves (but plateau after fairly few experience cycles, ibid.). How important is automatic learning in the context of failure learning? We expect some types of errors to diminish as operators gain experience. For instance, car drivers lower their accident risk within the first five years of driving, and we tend to ascribe this to success experiences. However, the failure learning studies have ignored the automatic learning effect. A general assumption is that performance improvements are due to active learning attempts. One of the most studied groups in the error research is nurses (e.g., Edmondson, 2004; Tucker $\&$ Spear, 2006); however, we see little discussion with regard to whether nurses' error rates go down with tenure in the profession. Surgeons demonstrate failure reduction over time, thus it would be surprising if we would not see the same for nurses with respect to errors.

However, if the link between errors and failures is weak, the effect of professional tenure may not be a reduction in errors but a reduction in errors that result in failed outcomes, that is, in converting potential failures into near-miss events.

Again, considering the difference between settings, is there less room for automatic learning in slow-learning settings, thus requiring more deliberate learning for failure reduction? Examining these questions is both theoretically and practically meaningful. These questions help to advance our understanding as to how different types of learning occur. The answers to these questions have implications for practices as they help to develop intervention in organizations to enhance failure learning.

\section{Motivation to learn from failure}


Scholars assume that safety and risk avoidance are central to any organization, such as airlines, mining companies, hospitals, or banks, and they often ignore that most organizations to some degree accept failure. Safer practices compete with productivity-enhancing investments and since viable operations are necessary for the future of organizations, productivity is usually prioritized over the potential risk of a future failure, impacting the motivation to invest in failure reduction (Haunschild et al., 2015). This is illustrated by airlines that experience more accidents after filing for Chapter 11 protection (ABCnews, 2005) and by a famous quote in the freight rail industry: "Uphill slow, downhill fast, freight comes first and safety last” (Ahear \& Schick, 2014). Low-prime-lending practices are risky behaviors that lead to short-term gains but jeopardize organizations and the banking industry. In other words, failure reduction attempts will almost always compete with other activities, which is a situation that we must acknowledge when theorizing about and investigating failure learning. In addition, some failures are seen as being unavoidable by managers, and they are relegated to productivity equations' error terms and more or less accepted as a necessary evil rather than something to improve upon (cf. Jovanovic \& Nyarko, 1995). Tradeoffs therefore help to explain the low motivation to reduce failure risks (Haunschild et al., 2015). In many settings, regulators move in to change the balance, for instance, imposing fines if safety targets are not met. However, it ultimately comes down to decisions that are made by individuals and organizations on the costs that they are ready to allocate to learning and further improving their learning rate.

This leads us to ask if slow-learning settings face stronger trade-offs between productivity-enhancing activities and failure reduction.

Motivation and the case of non-learning: is motivation THE key factor in failure learning? A handful of empirical studies describe settings without failure learning even when similar events provide learning opportunities (Baumol \& Starbuck, 2005; Tucker \& Edmondson 
2003). Their findings led some scholars to question if it failure learning is generally to be expected at all (Baumold \& Starbuck, 2005). Analyzing these studies, we find that they describe situations with low motivation to learn (Baumold \& Starbuck, 2005; Eggers \& Song, 2015), limited opportunity to learn in combination with low motivation to solve underlying problems (Tucker \& Edmondson, 2003) and potentially an inability to learn due to low motivation (Eggers \& Song, 2015). A conclusion is that failure learning is difficult since is only likely to happen when all three mechanisms are sufficiently activated, and that motivation is a necessary condition for deliberate learning.

In an in-depth case study of a large European telecom firm that suffered 14 strategic failures with no learning, Baumol \& Starbuck (2005) describe lack of systematic reporting about failed projects, lack of interest in better understanding what went wrong and managers making external attributions to explain away bad outcomes caused by internal factors. The authors find opportunity but low-to-no motivation to learn, which in the end resulted in no learning. Low motivation involved managers expecting that admitting failure would have negative career ramifications and possibly also harm the organization (many projects were imposed by external stake-holders and the firm was publicly listed). Applying Zhao \& Olivera's (2011) cost-benefit reasoning, the cost to the individual managers was high, the benefit to the organization not clear and, hence, low motivation to report was to be expected.

We find a similar argument around individuals using external attributions rather than changing their own behaviour among Chinese serial entrepreneurs (Eggers \& Song, 2015). Entrepreneurs with failed start-ups were less likely to alter the way they structured their companies than were entrepreneurs with successful start-ups. Rather, they pursued the same firm strategies and structures when launching a new venture which, in turn, increased the risk for failure. They preferred a new industrial setting which made the authors conclude that this inability to learn is in line with self-serving attribution theory: Using external attributions to 
avoid altering ones' method of working is an individual-level defense mechanism demonstrating both lack of motivation and inability to learn. In contrast, entrepreneurs with successful ventures who stayed in the same industry kept enjoying more success. Tucker and Edmondson (2003) report high incidences of errors without organizational-level learning in a study of nine hospitals known for nursing excellence. Front line nurses that constantly saw patients were confronted with many problems, such as errors and mistakes made by others, when executing their tasks. Surprisingly, the nurses' error learning was low despite their skill and motivation. The reason for low error learning is that the nurses solved the problems themselves on an ad hoc basis since they rarely had time to deal with the underlying causes. As a consequence, the same errors were repeatedly made and failure rates remained high. The insight from this study is that the nurses were highly motivated to execute their work, got a confidence boost in effectively managing problems created by others, and had little time to provide feedback to the organization. This is both a story of lack of motivation that emphasizes that the motivation in question is about addressing underlying problems caused by others, and that the support structure did not offer sufficient opportunity to get to the root cause of the problems, both in terms of managerial support but also the lack of time-based opportunity to analyze errors and come up with solutions to reduce their recurrence.

Across these three non-learning cases motivation plays different roles: ego protection, career protection, protecting the organization and focus on other parts of the job than error, or problem reduction. In what way besides motivation do these non-learning cases contrast with learning cases? Are there more competing motivations in non-learning cases?

Is it an illustration of how motivation is a necessary factor for learning to occur and without it neither opportunity nor ability matter? Also, how common are non-learning outcomes and 
when do they matter? In the telecom case, the firm still did well and clearly was not very concerned with the failed strategic projects. When do organizations ignore failures?

\section{The nature of the failure event}

We suggest three areas of research to expand how we study failure events to improve causality in studies: using counterfactuals by applying the process-outcome matrix in Table 2 when selecting events; extending our failure measures to also consider per-event learning; and standardizing or at least improving the measures of the learning process.

Selection of the dependent variable. Few learning studies allow for both successes and failures to be key events in the research design (Denrell, 2003). Most studies choose to focus on either successful or failed outcomes (sometimes controlling for the other), and the set of factors that cause such outcomes. However, to extend our understanding of the relationship between processes and outcomes, the inclusion of both types of events in the research design would allow for stronger causal linkages. Currently, this is done in studies in which an intervention is randomly assigned to different organizational units and the outcomes are monitored, such as the introduction of checklists in health care into one subset of hospitals, while the comparison group works as before, and the reduction of adverse events is monitored (cf. Walker, Reshamwalla \& Wilson, 2012). In checklist studies an outcome is either a success or a failure, thus the rate includes both possibilities while the focus remains on the effect of a single mechanism, the use of a checklist or not. The initiation of such studies are usually third-party organizations, such as the WHO, in the health care checklist example (WHO, 2017).

Including both successful and failed outcomes would also allow for a study of the role that is played by noise in the learning process (the off-diagonal outcomes in Table 2) to cover the full range of process-outcome combinations, thus allowing us to better understand disturbances in learning processes. 
Extending failure measures. The failure learning literature covers a diverse set of events, from bankruptcies to patient deaths to large-scale accidents that involve hundreds of victims who have been injured or killed. Some events occur once per hour and some occur once per week, while others occur once per decade. While the magnitude of events matter for learning, higher-impact events motivate organizations to respond more forcefully. An important question to ask is whether the sensitivity to failure events varies across industries, and, if so, what determines the level of sensitivity. In settings with many adverse events that are caused less by errors and more by the nature of operations (very elderly patients dying in health care, for instance), we expect a greater insensitivity to the adverse events that are caused by errors. Three dimensions that should matter when considering events are (1) the frequency with which failures occur; (2) the frequency with which adverse events that are NOT caused by errors occur; (3) the magnitude of the failure, including the failure magnitude when compared to industry averages (killed, injured, failure costs). Few studies show us how much a single failure event affects learning (see Dahlin \& Baum, 2012 for an exception), which might provide a clue to how frequency and magnitude matter. A per-event measure would also make comparisons across setting more applicable. Here, a meta-analysis could reveal the different effects of failure events.

We expect the industries that experience a combination of high failure volume and high spurious failure volume to have an elevated error acceptance. Elevated error acceptance reduces the motivation to learn, which would explain a lower learning rate in such settings.

Are learning rates overestimated? A paper critiquing the methods used in econometric studies of failure learning, argues that statistical estimations used in failure learning studies are prone to yielding falsely positive results (Bennett $\&$ Snyder, 2017). The authors point out that the classical learning model where current performance (cost per unit) is a logarithmic 
function of accumulated experience (number of units produced) has some econometric issues when translated to failure learning and risk overstating the case for failure learning. Similarly, they point out the risk for false positive coefficient results increase when including successful as well as unsuccessful learning opportunities in the same equation. They recommend using moving time windows of past failures, and separating the success and failure opportunities into different estimations. Most studies already use moving windows and also discount events further back in time (albeit they do this for theoretical and data rather than estimation reasons) (cf. Baum \& Dahlin, 20017; Kim \& Miner, 2007).

Even if Bennett and Snyder overstate the risk of falsely positive results, their paper raises a more fundamental question about econometric failure learning models. Usually a learning curve is assumed (often without this functional form being established as the one best-fitting the data) which means that a key assumption is that success and failure learning follow the same learning pattern. Similarly, when including both successful and failed prior events these are seen as additive which is an untested assumption. For instance, in traditional success learning, failed outcomes can be seen as reducing the learning rate but it is usually relegated to the error term. To model the interaction between success and failure, we need to develop new models accounting for both failure and learning as potential complements rather than substitutes. This way we could for instance see spill-overs from number of successful repetitions in learning-by-doing (such as driving a car) - when skills increase, errors and mistakes decrease as a function of more successful events. Rather than substitutes, there is complementarity with success learning leading to fewer failures and also enhancing failure learning. Conversely, we can observe that failure has a complex effect on normal operations, slowing down success learning since overall output might be reduced after a serious accident. The recommendation from Bennett and Snyder (2017) is to, for econometric reasons, not include both successful and failed events in the same estimations, we would argue that they 
should also be estimated separately for theoretical reasons - we simply don't know how they relate.

Measuring failure and its responses. The empirical studies on failure learning face two measurement issues. First, individuals and organizations often fail to identify or report all failure events. This makes examining failures' effects on learning processes more of a challenge. Common approaches to collecting failure and error data include using public archival data (e.g., Baum \& Dahlin, 2007; Desai, 2015; Lawton et al., 2012), experimental designs (Dillon \& Tinsley, 2008; Ellis et al., 2006), or employee recall (Ginsburg, et al., 2010). Archival data and employee recall increase under-reporting biases, and the question is how to account for this when interpreting studies. Audits are, for instance undertaken in a number of industries, with the Federal Railroad Administration performing spot-checks on regulation compliance (FRA, 2017). Legal cases where non-reporting leads to penalties usually state the expected underreporting. Union representatives also have addressed underreporting.

Second, our review revealed that there is a lack of common measures with regard to failure learning behaviors, such as the schemas that are used when responding to failures. Without common measures, it is difficult to compare the results from studies with different research settings. With few exceptions (cf. Ginsburg, et al, 2010; Shepherd et al., 2011) most studies measure broad learning behaviors, such as whether employees can challenge work processes or if they have improved work procedures, rather than learning behaviors that are specifically related to failures, such as the identification of an adverse event, cause analysis and corrective action. Most importantly, to better understand errors and failure learning requires a research design with an explicit link between failure events and the different 
elements of learning behavior, such as Israeli flight crews' post-event analyses (Ellis et al., 2006).

\section{CONCLUSION}

Reviewing the literature on error and failure learning, we clustered learning mechanisms into three categories of opportunity to learn (the factors of information and time), motivation to learn (willingness to act) and ability to learn (competence to act). Failure and error learning have been studied across academic areas and address multiple levels of analysis, from individual, group and organizational perspectives. While motivation and ability factors dominate studies at the individual and group levels of analysis, opportunity factors dominate studies at the organizational level. Studies in health management are also concerned with procedure-level studies, with a wealth of data showing time trends for procedures on the national level, where learning diverges greatly across treatment types from negative, over no improvement, to some positive learning (Downey et al., 2012).

In summary, the findings suggest that more information about errors and failures in the form of one's own and others' prior failures or near failures facilitate learning. They go on to report that leaders and organizations with a punitive attitude toward errors and failures obtain less information because individuals in such organizations consider the cost of reporting to be too high. Additionally, they state that the ability to process and learn from errors and failures is partly based on attribution and inherent attitudes; however, this ability can be boosted through active post-event reviews. We argue that the cross-industry differences in learning rates depend on a number of factors. Among those factors, a noisy learning environment in which organizations experience spurious successes and spurious failures exerts a strong influence on failure learning. Noisy information about cause-effect makes failure information more difficult to interpret, which lowers learning opportunities and 
ability. Spurious successes and failures also create ambiguity, which lowers the motivation to learn because the awareness of weak error-failure connections risks leading to normalized deviance, and it can also lower individuals' motivations to report errors and failures.

An organization that seeks to enhance error and failure learning should analyze the causes of its most common errors and failures. To maximize the opportunity to learn, the organization should not only study its own but also the events of similar organizations. Further, including near-misses would add information and suggestions for ways to avoid an adverse outcome after a process error has occurred. When attributing causes, management must ensure that operators are not unduly blamed and if the cause is found to be operator error, look for systematic such errors to find if there are structural or organizational factors leading to operator error.

We propose a number of unexplored research areas in error and failure learning, some of which are related to a lack of linkages across academic disciplines. In short: management scholars tend to ignore the role that is played by regulators in failure reduction; policy scholars tend to ignore organizational differences and the role that is played by management in failure reduction; safety scholars have devised methods for the transfer of learning and for the development of ability; however, they have not yet fully established the efficacy of these tools. To that end, scholars across academic disciplines have "failed" to learn from each other's failure research. Through our review, we have found fruitful opportunities for future research to learn from the extant failure studies to enhance our understanding of failure learning in organizations. 


\section{References}

Ahear, A. \& Schick T. 2014. Rail workers raise doubt about safety culture as oil trains roll on. EarthFix, July 2. Retrieved February 25, 2015 from http:/www.opb.org/news/article/workersquestion-safety-culture-in-railroads-hauli/

Argote, L. 2012. Organizational learning: Creating, retaining and transferring knowledge. New York, NY: Springer.

Argote L, McEvily B, and Reagans R. 2003. Managing knowledge in organizations: An integrative framework and review of emerging themes, Management Science, vol. 49, no. 4, pp. 571-582.

Argote, L., \& Todorova, G. 2007. Organizational learning. International review of industrial and organizational psychology, 22, 193.

Arrow, K. 1962. The Economic Implications of Learning by Doing. Review of Economic Studies, 29, 166-170.

Baker D. P., Day R., Salas E. 2006. Teamwork as an Essential Component of High-Reliability Organizations. HSR: Health Services Research. 41:4, II

Baum, J. A. C., \& Dahlin, K. B. 2007. Aspiration performance and railroads' patterns of learning from train wrecks and crashes. Organization Science, 18(3): 368-385,543-544.

Banja, J. 2010. The normalization of deviance in healthcare delivery. Business Horizons, 53(2): 159 .

Baum, J. A. C. and Ingram P. 1998. 'Survival-enhancing learning in the Manhattan hotel industry, 1898-1980’. Management Science, 44, pp. 996-1016.

Baumard, P., \& Starbuck, W. H. 2005. Learning from failures: Why it may not happen. Long Range Planning, 38(3), 281-298.

Bennett, V. M., \& Snyder, J. (2017). The Empirics of Learning from Failure. Strategy Science, 2(1), 1-12. 
Bernstein, E. S. 2012. The transparency paradox: A role for privacy in organizational learning and operational control. Administrative Science Quarterly, 57(2), 181-216.

Binder, L. 2013. Stunning news on preventable deaths in hospitals. Forbes. http://www.forbes.com/sites/leahbinder/2013/09/23/stunning-news-on-preventable-deaths-in-

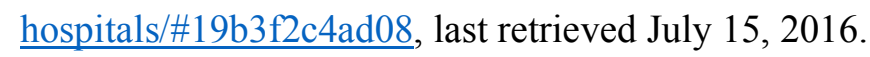

Blinder, A. 2016. Donald Blankenship Sentenced to a Year in Prison in Mine Safety Case https://www.nytimes.com/2016/04/07/us/donald-blankenship-sentenced-to-a-year-in-prison-

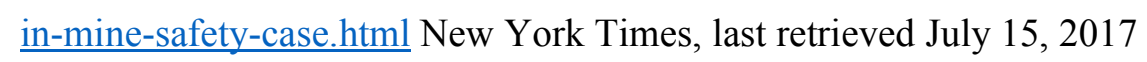

Blumberg, M., \& Pringle, C. D. 1982. The missing opportunity in organizational research: Some implications for a theory of work performance. Academy of Management Review, 7: $560-569$.

Buljac-Samardzic, M., van Woerkom, M., \& Paauwe, J. 2012. Team safety and innovation by learning from errors in long-term care settings. Health Care Management Review, 37(3): 280-291.

Cannon, M. D., \& Edmondson, A. C. 2001. Confronting failure: Antecedents and consequences of shared beliefs about failure in organizational work groups. Journal of Organizational Behavior, 22(2): 161-177.

Cannon, M. D., \& Edmondson, A. C. 2005. Failing to learn and learning to fail (intelligently): How great organizations put failure to work to innovate and improve. Long Range Planning, $38(3), 299-319$

Carmeli, A., \& Gittell, J. H. 2009. High-quality relationships, psychological safety, and learning from failures in work organizations. Journal of Organizational Behavior, 30(6): 709-729. 
Carmeli, A., Tishler, A., \& Edmondson, A. C. 2012. CEO relational leadership and strategic decision quality in top management teams: The role of team trust and learning from failure. Strategic Organization, 10(1), 31-54.

Carroll, J. B. 1963. A model of school learning. Teachers college record.

Chuang, Y., \& Baum, J. A. C. 2003. It's all in the name: Failure-induced learning by multiunit chains. Administrative Science Quarterly, 48(1): 33-59.

Chuang, Y., Ginsburg, L., \& Berta, W. B. 2007. Learning from preventable adverse events in health care organizations: Development of a multilevel model of learning and propositions.

Health Care Management Review, 32(4): 330-340.

Clay-Williams, R., \& Colligan, L. 2015. Back to basics: checklists in aviation and healthcare. BMJ Qual Saf, 24(7), 428-431.

Cyert, R. M., J. G. March. 1963. A Behavioral Theory of the Firm. Prentice-Hall, Englewood Cliffs, NJ.

Dahlin, K.B. and Roulet, T.J., 2014. Different Slopes for Different Folks? Train Accident Learning Curves. Academy of Management Proceedings (Vol. 2014, No. 1, p. 11938). Academy of Management.

Degani, A. and Wiener E. L. 1993. Cockpit checklists: concepts, design and use. Human Factors 35(2), pp. 28-43.

Dekker, S. 2011. The criminalization of human error in aviation and healthcare: A review. Safety science, 49(2), 121-127.

Denrell, J. 2003. Vicarious learning, undersampling of failure, and the myths of management. Organization Science, 14(3), pp. 227-243.

Desai, V. 2011. Mass Media and Massive Failures: Determining Organizational Efforts to Defend the Field's Legitimacy following Crises. Academy of Management Journal 54: 263 278. 
Desai, V. 2014. The impact of media information on issue salience following other organizations' failures. Journal of Management, 40(3), 893-918.

Desai, V. 2015. Learning through the Distribution of Failures within an Organization:

Evidence from Heart Bypass Surgery Performance. Academy of Management Journal 58: 1032-1050.

Desai, V. 2016. Learning to learn from failures: the impact of operating experience on railroad accident responses. Industrial and Corporate Change, 25(2), 199-226.

Dillon, R. L., \& Tinsley, C. H. 2008. How near-misses influence decision making under risk: A missed opportunity for learning. Management Science, 54(8): 1425-1440.

Downey, J. R., Hernandez-Boussard, T., Banka, G., \& Morton, J. M. (2012). Is patient safety improving? National trends in patient safety indicators: 1998-2007. Health services research, 47(1pt2), 414-430.

van Dyck, Frese, M., \& Baer, S. Sonnentag. 2005. Organizational error management culture and its impact on performance: A two-study replication. Journal of Applied Psychology, 90(6): 1228-1240.

Edmondson, A. C. 1996. Learning from mistakes is easier said than done: Group and organizational influences on the detection and correction of human error. The Journal of Applied Behavioral Science, 32(1), 5-28.

Edmondson, A. C., Bohmer, R. M., \& Pisano, G. P. 2001. Disrupted routines: Team learning and new technology implementation in hospitals. Administrative Science Quarterly, 46(4), $685-716$.

Edmondson, A. C., \& Lei, Z. 2014. Psychological safety: The history, renaissance, and future of an interpersonal construct. Annual Review of Organizational Psychology \& Organizational Behavior, 1(1), 23-43. 
Eggers, J. P., \& Song, L. 2015. Dealing with Failure: Serial Entrepreneurs and the Costs of Changing Industries Between Ventures. Academy of Management Journal, 58(6), 17851803.

Ellis, S., Mendel, R., \& Nir, M. 2006. Learning from successful and failed experience: the moderating role of kind of after-event review. Journal of Applied Psychology, 91(3), 669.

Ellis, S., \& Davidi, I. 2005. After-event reviews: Drawing lessons from successful and failed experience. Journal of Applied Psychology, 90(5): 857-871.

Forgas, J. P. 1995. Mood and judgment: the affect infusion model (AIM). Psychological bulletin, 117(1), 39.

FRA. 2016. FRA Issues New Rule Requiring Passenger Railroads to Proactively Identify and Reduce Safety Risks. Federal Railroad Agency, Press Release FRA 21-16, July 2016 https://www.fra.dot.gov/eLib/details/L18291\#p1_z25_gD_1PR_y2016

Frese, M., \& Keith, N. 2015. Action errors, error management, and learning in organizations. Annual review of psychology, 66, 661-687.

Gersick, C. J., \& Hackman, J. R. 1990. Habitual routines in task-performing groups. Organizational behavior and human decision processes, 47(1), 65-97.

Ginsburg, L. R., Chuang, Y., Norton, P. G., Berta, W., Tregunno, D., Ng, P., \& Richardson, J. 2009. Development of a measure of patient safety event learning responses. Health Services Research, 44(6): 2123-2147.

Ginsburg, L., Chuang, Y.T., Berta, W.B., Norton, P.G., Ng, P., Tregunno, D., and Richardson, J., 2010. The relationship between organizational leadership for safety and learning from patient safety events. Health Services Research, 45: 607-632.

Gully, S. M., Payne, S. C., K Lee Kiechel Koles, \& Whiteman, J. K. 2002. The impact of error training and individual differences on training outcomes: An attribute-treatment interaction perspective. Journal of Applied Psychology, 87(1): 143-155. 
Haunschild, P. R., \& Rhee, M. 2004. The role of volition in organizational learning: The case of automotive product recalls. Management Science, 50(11), 1545-1560.

Haunschild, P.R., Polidoro Jr. F. and D. Chandler. 2015. Organizational Oscillation Between Learning and Forgetting: The Dual Role of Serious Errors. Organization Science, 26(6).

Haunschild, P.R. and B. Sullivan. 2002. Learning from complexity: Effects of accident/incident heterogeneity on airline learning. Administrative Science Quarterly 49: 607-643.

Heimbeck, D., Frese, M., Sonnentang, S., \& Keith, N. 2003. Integrating errors into the training process: The function of error management instructions and the role of goal orientation. Personnel Psychology, 56(2): 333-361.

Hodgkinson, G. P., \& Wright, G. 2002. Confronting strategic inertia in a top management team: Learning from failure. Organization Studies, 23(6), 949-977.

Hoff, T., Jameson, L., Hannan, E., \& Flink, E. 2004. A review of the literature examining linkages between organizational factors, medical errors, and patient safety. Medical Care Research and Review, 61(1), 3-37.

Hofmann, D.A. \& Frese, M. 2011. Errors, error taxonomies, error prevention, and error management: Laying the groundwork for discussing errors in organizations. In D. Hofmann \& M. Frese (eds), Errors in organizations, New York: Routledge, pp: 1-44.

Hofmann, D. A., \& Mark, B. 2006. An investigation of the relationship between safety climate and medication errors as well as other nurse and patient outcomes. Personnel Psychology, 59(4): 847-869.

Hofmann, D. A., \& Stetzer, A. 1996. A cross - level investigation of factors influencing unsafe behaviors and accidents. Personnel Psychology, 49(2), 307-339.

Huber, G. P. 1991. Organizational learning: The contributing processes and the literatures. Organization science, 2(1), 88-115. 
Iedema, R. A. M., Jorm, C., Long, D., Braithwaite, J., Travaglia, J., \& Westbrook, M. 2006. Turning the medical gaze in upon itself: root cause analysis and the investigation of clinical error. Social science \& medicine, 62(7), 1605-1615.

Ilgen, D., \& Davis, C. 2000. Bearing bad news: Reactions to negative performance feedback. Applied Psychology, 49(3), 550-565.

Ito, T. A., Larsen, J. T., Smith, N. K., \& Cacioppo, J. T. 1998. Negative information weighs more heavily on the brain: the negativity bias in evaluative categorizations. Journal of personality and social psychology, 75(4), 887.

Jones, E. E.; Harris, V. A. (1967). The attribution of attitudes. Journal of Experimental Social Psychology. 3 (1): 1-24.

Jovanovic B, and Nyarko Y. 1995. A Bayesian learning model fitted to a variety of empirical learning curves. Brookings Papers on Economic Activity Microeconomics, 1995: 247-305.

Kanfer, R., \& Ackerman, P. L. 1989. Motivation and cognitive abilities: An integrative/aptitude-treatment interaction approach to skill acquisition. Journal of applied psychology, 74(4), 657.

Katz-Navon, T., Naveh, E., \& Stem, Z. 2009. Active learning: When is more better? The case of resident physicians' medical errors. Journal of Applied Psychology, 94(5): 1200-1209.

KC, D., Staats, B. R., \& Gino, F. 2013. Learning from my success and from others' failure: Evidence from minimally invasive cardiac surgery. Management Science, 59(11), 2435 2449.

Keith, N., \& Frese, M. 2005. Self-regulation in error management training: emotion control and metacognition as mediators of performance effects. Journal of Applied Psychology, $90(4), 677$.

Kerr, A. 2009. A problem shared...? Teamwork, autonomy and error in assisted conception. Social Science \& Medicine, 69(12), 1741-1749. 
Kessels-Habraken, M., Van der Schaaf, T., De Jonge, J., \& Rutte, C. 2010. Defining near misses: Towards a sharpened definition based on empirical data about error handling processes. Social science \& medicine, 70(9), 1301-1308.

Khatri, N., Brown, G.D. and Hicks, L.L., 2009. From a blame culture to a just culture in health care. Health care management review, 34(4), pp.312-322.

Kim, J. \& Miner, A. S. 2007. Vicarious learning from the failures and near-failures of others: Evidence from the U.S. commercial banking industry. Academy of Management Journal, 50(3): $687-714$.

Kohn, L.T., Corrigan, J. and M.S. Donaldson. 2000. To err is human: Building a safer health system. Washington, D.C.: National Academy Press.

Kralewski, J. E., Dowd, B. E., Heaton, A., \& Kaissi, A. (2005). The influence of the structure and culture of medical group practices on prescription drug errors. Medical care, 43(8), 817825.

Lapré, M.A., Mukherjee, A. S. and L. N. Van Wassenhove. 2000. Behind the Learning Curve: Linking Learning Activities to Waste Reduction. Management Science Vol. 46, No. 5, pp. $597-611$

Lawton, R., Carruthers, S., Gardner, P., Wright, J. \& McEachan R. (2012)

Identifying the Latent Failures Underpinning Medication Administration Errors: An

Exploratory Study. HSR: Health Services Research. 47:4

Leape, L. L. 1994. Error in medicine. Journal of the American Medical Association. 273(23): 1851-1857.

Leape, L.L. 2014. The checklist conundrum. New England Journal of Medicine 2014;370:1063 4. doi:10.1056/NEJMe13158 
Lei, Z., Naveh, E., \& Novikov, Z. 2016. Errors in Organizations An Integrative Review via Level of Analysis, Temporal Dynamism, and Priority Lenses. Journal of Management, 0149206316633745.

Loewenstein, G. F., Weber, E. U., Hsee, C. K., \& Welch, N. 2001. Risk as feelings. Psychological bulletin, 127(2), 267.

Madsen, P. M., \& Desai, V. 2010. Failing to learn? The effects of failure and success on organizational learning in the global orbital launch vehicle industry. Academy of Management Journal, 53(3): 451-476.

Madsen, P., Dillon, R. L., \& Tinsley, C. H. 2016. Airline Safety Improvement Through Experience with Near-Misses: A Cautionary Tale. Risk analysis, 36(5), 1054-1066.

Madsen, P. M. 2009. These lives will not be lost in vain: Organizational learning from disaster in US coal mining. Organization Science, 20(5), 861-875.

Malone, D. C., Abarca, J., Skrepnek, G. H., Murphy, J. E., Armstrong, E. P., Grizzle, A. J., ... \& Woosley, R. L. (2007). Pharmacist workload and pharmacy characteristics associated with the dispensing of potentially clinically important drug-drug interactions. Medical care, 45(5), 456-462.

Maxfield, D., Grenny, J., McMillan, R., Patterson, K., \& Switzler, A. 2005. Silence kills. Vital Smarts, Crucial Conversations.

Mitsuhashi, H., 2012. Almost identical experience biases in vicarious learning. Industrial and Corporate Change, 21(4), pp.837-869.

Morey, J. C., Simon, R., Jay, G. D., Wears, R. L., \& et al. 2002. Error reduction and performance improvement in the emergency department through formal teamwork training: Evaluation results of the MedTeams project. Health Services Research, 37(6): 1553-1581. 
Muehlfeld, K., Sahib, P. R., \& Van Witteloostuijn, A. 2012. A contextual theory of organizational learning from failures and successes: A study of acquisition completion in the global newspaper industry, 1981-2008. Strategic Management Journal, 33(8): 938-964. Naquin, C. E., \& Tynan, R. O. 2003. The team halo effect: Why teams are not blamed for their failures. Journal of Applied Psychology, 88(2): 332-340.

Neal, A., \& Griffin, M. A. 2006. A study of the lagged relationships among safety climate, safety motivation, safety behavior, and accidents at the individual and group levels. Journal of applied psychology, 91(4), 946.

Nisbett, R. E., \& Ross, L. 1980. Human inference: Strategies and shortcomings of social judgment. Prentice-Hall.

Paget, M. A. 1988. The unity of mistakes. Philadelphia: Temple University Press. Perrow, C. 1999. Normal accidents: Living with high-risk technologies. Princeton, N.J.: Princeton University Press.

Pisano, G. P., Bohmer, R. M., \& Edmondson, A. C. 2001. Organizational differences in rates of learning: Evidence from the adoption of minimally invasive cardiac surgery. Management Science, 47(6), 752-768.

Probst, T.M., 2015. Organizational safety climate and supervisor safety enforcement: Multilevel explorations of the causes of accident underreporting. Journal of applied psychology, 100(6), p.1899.

Ramanujam, R., \& Goodman, P. S. 2003. Latent errors and adverse organizational consequences: A conceptualization. Journal of Organizational Behavior, 24(7): 815-836. Ramanujam, R. 2003. The effects of discontinuous change on latent errors in organizations: The moderating role of risk. Academy of Management Journal, 46(5), 608-617. 
Rasmussen, J., Nixon, P. and F. Warner. 1990. Human Error and the Problem of Causality in Analysis of Accidents, Philosophical Transactions of the Royal Society, London, Volume B 327, 449-462.

Rathert, C., \& May, D. R. 2007. Health care work environments, employee satisfaction, and patient safety: Care provider perspectives. Health care management review, 32(1), 2-11.

Reason, J. T. 1990. Human error. New York; Cambridge University Press.

Reason, J. 1997. Managing the risks of organizational accidents. Burlington, VT: Ashgate Publishing Co.

Reinholt, M. I. A., Pedersen, T., \& Foss, N. J. 2011. Why a central network position isn't enough: The role of motivation and ability for knowledge sharing in employee networks. Academy of Management Journal, 54(6), 1277-1297.

Rerup, C. 2006. Success, Failure And The Gray Zone: How Organizations Learn Or Don't From Ambiguous Experience. In Academy of Management Proceedings (Vol. 2006, No. 1, pp. BB1-BB6). Academy of Management.

Rhee, M. 2009. Does reputation contribute to reducing organizational errors? A learning approach. Journal of Management Studies, 46(4), 676-703.

Ron, N., Lipshitz, R., \& Popper, M. 2006. How organizations learn: Post-flight reviews in an F-16 fighter squadron. Organization Studies, 27(8), 1069-1089.

Roulet, T. J. 2015. “What good is Wall Street?” Institutional contradiction and the diffusion of the stigma over the finance industry. Journal of Business Ethics, 130(2), 389-402.

Salancik, G. R., \& Meindl, J. R. 1984. Corporate attributions as strategic illusions of management control. Administrative science quarterly, 238-254.

Shepherd, D. A., Patzelt, H., \& Wolfe, M. 2011. Moving forward from project failure: Negative emotions, affective commitment, and learning from the experience. Academy of Management Journal, 54(6): 1229-1259. 
Shymko, Y., \& Roulet, T. J. (2017). When does Medici hurt DaVinci? Mitigating the signaling effect of extraneous stakeholder relationships in the field of cultural production. Academy of Management Journal. August 2017.

Silbey, S. S. 2009. Taming Prometheus: Talk about safety and culture. Annual Review of Sociology, 35: 341-369.

Sinclair, G., Klepper, S.\& Cohen, W. 2000. What's experience got to do with it? Sources of Cost Reduction in a Large Specialty Chemicals Producer. Management Science, 46(1): 2845

Sitkin, S.B. 1992. Learning through failure: The strategy of small losses. Research in Organizational Behavior, 14: 231-266.

Stan, M., \& Vermeulen, F. 2013. Selection at the gate: Difficult cases, spillovers, and organizational learning. Organization Science, 24(3), 796-812.

Stern, Z., Katz-Navon, T., \& Naveh, E. 2008. The influence of situational learning orientation, autonomy, and voice on error making: The case of resident physicians.

Management Science, 54(9), 1553-1564.

Thomassen Ø, Storesund A, Søfteland E, and Brattebøl, G. 2014. The effects of safety checklists in medicine: a systematic review. Acta Anaesthesiologica Scandinavica 2014;58:5-18. doi:10.1111/aas.12207

Thompson, P. (2001). How much did the Liberty shipbuilders learn? New evidence for an old case study. Journal of Political Economy, 109(1), 103-137.

Thompson, P. 2012. The Relationship between Unit Cost and Cumulative Quantity and the Evidence for Organizational Learning-by-Doing, Journal of Economic Perspectives, American Economic Association, vol. 26(3), pages 203-24, Summer Tjosvold, D., Yu, Z. Y., \& Hui, C. 2004. Team learning from mistakes: the contribution of cooperative goals and problem-solving. Journal of Management Studies, 41(7), 1223-1245 
Thornlow, D. K., \& Merwin, E. 2009. Managing to improve quality: the relationship between accreditation standards, safety practices, and patient outcomes. Health care management review, 34(3), 262-272.

Tucker, A. L., \& Edmondson, A. C. 2003. Why hospitals don't learn from failures: organizational and psychological dynamics that inhibit system change. California management review, 45(2), 55-72.

Tucker, A. L., \& Spear, S. J. 2006. Operational failures and interruptions in hospital nursing. Health services research, 41(3p1), 643-662.

Vaughan, D. 1996. The Challenger Launch Decision: Risky Technology, Culture, and Deviance at NASA."

Vogus, T. J., \& Sutcliffe, K. M. 2007. The impact of safety organizing, trusted leadership, and care pathways on reported medication errors in hospital nursing units. Medical Care, 45(10): $997-1002$.

Walker, I. A., Reshamwalla, S., Wilson, I. H. 2012. Surgical safety checklists: do they improve outcomes?. British Journal of Anaesthesy 2012; 109 (1): 47-54. doi:

10.1093/bja/aes 175

WHO, 2017. The World Health Organization website, http://www.who.int/patientsafety/safesurgery/ss_checklist/en/last accessed June 15, 2017. Wright, T. P. 1936. Factors affecting the cost of airplanes. Journal of Aeronautical Sciences, 3(4): $122-128$.

Yelle, L. E. 1979. The learning curve: Historical review and comprehensive survey. Decision Sciences, 10(2), 302-328.

Zhao, B., \& Olivera, F. 2006. Error reporting in organizations. Academy of Management Review, 31(4), 1012-1030. 
1

2

3

4

5

6

7

8

9

10

Zhao, B. 2011. Learning from errors: The role of context, emotion, and personality. Journal of Organizational Behavior, 32(3): 435.

Zheng, Y. Miner, A. \& George, G. 2013. Does the learning value of individual failure experience depend on group-level success? Insights from a University Technology Transfer Office. Industrial \& Corporate Change. doi:10.1093/icc/dtt003

Zohar, D. 2002. The effects of leadership dimensions, safety climate, and assigned priorities on minor injuries in work groups. Journal of Organizational Behavior, 23(1), 75-92.

Zohar, D., \& Luria, G. 2005. A multilevel model of safety climate: cross-level relationships between organization and group-level climates. Journal of applied psychology, 90(4), 616. 
Table 1. Factors investigated in failure learning studies classified by level of analysis and mechanisms.

Opportunity

\begin{tabular}{ll}
\hline \hline Individual & Perceived autonomy (Stern at el., 2008) \\
level & Situational learning (Stern at el., 2008) \\
& Experience (KC, Staats, \& Gino 2013)
\end{tabular}

Group level
Motivation

Motivation to learn (Zhao, 2011) and safety

motivation (Buljac-Samardzic, et al. 2012;

Neal \& Griffin, 2006; Probst, 2015)

Attribution (Ilgen and Davis, 2000; Nisbett and

Ross, 1980; Ellis, Mendel \& Nir, 2006; KC, Staats,

\& Gino 2013; Naquin \& Tynan, 2003)

Emotion (Edmondson, 1996; Paget, 1988; Keith \&

Frese, 2005; Neal \& Griffin, 2006; Shepherd et al.,

2011; Zhao, 2011)

Psychological safety (Carmeli \& Gittell, 2009)

Perception of outcomes (Dillon \& Tinsley, 2008)

Coping orientation (Shepherd et al. 2011)

Member rotation (Argote \& Todorova, 2007)

Group diversity and intergroup-linkages (Chuang et

al. 2007; Tucker \& Edmondson, 2003)

Team stability (Edmondson, 1996)

Routines to gather information (Lawton, et al. 2012;

Edmondson, et al 2001; Tucker \& Spear, 2006)

Autonomy (Kerr, 2009) and load (Malone et al.

2007)
Group norms and team orientation (Katz-Navon,

al., 2009; Vogus \& Sutcliffe, 2007; Zohar, 2002.

Tjosvold et al. 2004)

Psychological safety (Edmondson, et al. 2001)

Tacit belief about failure (Cannon \& Edmondson,

2001; Edmondson, et al., 2001)

Leadership style (Cannon \& Edmondson, 2001;

Katz-Navon et al., 2009; Carmeli et al., 2012)

Safety climate (Zohar \& Luria, 2005)

Status dynxamics (Edmondson, et al. 2001)

Routines (Gersick \& Hackman, 1990)

Debriefing and reviewing abilities (Ron, et al. 2006)

Resistance to change (Hodgkinson \& Wright, 2002)

Workload (Lawton et al., 2012) and autonomy

(Kerr, 2009)
Ability

Training (Gully, et al., 2002; Keith \& Frese, 2005)

After-event reviews (Ellis \& Davidi, 2005; Ellis, Mendel, \& Nir, 2006)

Coping orientation (Shepherd, et al., 2011)

Relationships with others (Carmeli \& Gittell, 2009)
Failure climate (Buljac-Samardzic et al., 2012)

Leadership style (Buljac-Samardzic et al., 2012; Zhao, 2011;

Cannon \& Edmondson, 2001)

Training (Morey, et al. 2002)

Membership stability (Buljac-Samardzic et al., 2012)

Understanding of team process (Baker et al., 2006)

Workload (Lawton et al., 2012) and work process

(Edmondson, 1996)

Coordination and communication (Baker et al. 2006) to develop cooperative goals (Tjosvold et al. 2004) 
Organizational Own and others' failure experience and processes to $\begin{array}{ll}\text { level } & \text { collect information on those failures (Tucker \& } \\ \text { (includes } & \text { Spear, 2006; Baum \& Dahlin, 2007; Chuang \& }\end{array}$ inter- Baum, 2003; Haunschild \& Rhee, 2004; Haunschild

organizational \& Sullivan, 2002; Kim \& Miner, 2007; Madsen \& factors)

Desai, 2010; Madsen, Dillon \& Tinsley, 2016)
Performance aspirations (Baum \& Dahlin, 2007) Own success experience (Madsen \& Desai, 2010;

Pisano et al., 2001)

Recency of event (Haunschild, Polidoro \& Chandler, 2015)

Magnitude of event (Desai, 2011; Madsen, 2009)

Complexity of problems (Stan \& Vermuelen, 2013)

Organizational size (Desai, 2009; Slonim, 2007)

Near failures / near misses (Kim \& Miner, 2007;

Kessels-Habraken, et al. 2010) Media attention (Desai, 2011 and Desai 2014; opposite results)

Reputation (Haunschild \& Rhee, 2004; Rhee, 2009)

Safety climate (Hofman \& Stetzer, 1998)

Organizational form (Hanschild \& Sullivan, 2002)

Failure climate (Khatri et al., 2009)

Error management culture (Dyck et al., 2005)

Other's similar errors (Mitsuhashi, 2011)

Culture, work load (Kralewski, et al. 2005; Malone et al.

\section{7)}

Post-experience reviews (Ron, Lipshitz \& Popper, 2006) and external pressures (Haunschild \& Rhee, 2004).

Patient-centered hospitals, climate (Rahert \& May, 2007; Lawton et al., 2012)

Standardized procedures/protocols (Thornlow \& Merlin, 2009)

Organizational size (Ginsburg, et al., 2010) 
Table 2. $2 \times 2$ table of four process and outcome combinations.

\begin{tabular}{|c|c|c|c|}
\hline & & \multicolumn{2}{|c|}{ Outcome of event } \\
\hline & & Success & Failure \\
\hline & Correct & 1. Traditional learning & 2. Spurious failure \\
\hline & Faulty & 3. Spurious success & $\begin{array}{l}\text { 4. Traditional failure } \\
\text { learning }\end{array}$ \\
\hline
\end{tabular}

1

2

5

6

7

8

10

11

12

13

14

15

16

17

18

19

20

21

22

23

24

25

26

27

28

29

30

31

32

33

34

35

36

37

38

39

40

41

42

43

44

45

46

47

48

49

50

51

52

53

54

55

56

57

58

59

60 


\begin{tabular}{|c|c|c|c|c|c|c|c|c|}
\hline Authors & JOURNAL & YEAR & $\begin{array}{l}\text { LEVEL OF } \\
\text { ANALYSIS }\end{array}$ & $\mathbf{O} / \mathbf{M} / \mathbf{A}^{1}$ & DATA/SETTING & METHOD & $\mathbf{N}$ & RESULT \\
\hline Edmondson & $\begin{array}{l}\text { Journal of } \\
\text { Applied } \\
\text { Behavioral } \\
\text { Science }\end{array}$ & 1996 & Group & $\mathrm{O}, \mathrm{A}$ & Patient care groups & Survey & 8 units & $\mathrm{L}=\mathrm{O}, \mathrm{A}$ \\
\hline Hofman \& Stetzer & $\begin{array}{l}\text { Academy of } \\
\text { Management } \\
\text { Journal }\end{array}$ & 1998 & Group & M & Utility company & $\begin{array}{l}\text { Field } \\
\text { experiment }\end{array}$ & $\begin{array}{l}\text { Safety } \\
\text { communication and } \\
\text { attributions in } 159 \\
\text { groups }\end{array}$ & $\mathrm{L}: \mathrm{A} \rightarrow \mathrm{M}$ \\
\hline $\begin{array}{l}\text { Edmondson, Bohmer } \\
\text { \& Pisano }\end{array}$ & $\begin{array}{l}\text { Administrative } \\
\text { Science } \\
\text { Quarterly }\end{array}$ & 2001 & Group & M & Team in hospitals & Qualitative & 16 hospitals & $\mathrm{L}=\mathrm{M}$ \\
\hline $\begin{array}{l}\text { Cannon \& } \\
\text { Edmondson }\end{array}$ & $\begin{array}{l}\text { Journal of } \\
\text { Organizational } \\
\text { Behavior }\end{array}$ & 2001 & Group & $\mathrm{M}, \mathrm{A}$ & Organization teams & Field study & 51 groups & $\mathrm{L}=\mathrm{M}+\mathrm{A}$ \\
\hline $\begin{array}{l}\text { Haunschild \& } \\
\text { Sullivan }\end{array}$ & $\begin{array}{l}\text { Administrative } \\
\text { Science } \\
\text { Quarterly }\end{array}$ & 2002 & Organization & $\mathrm{O}, \mathrm{A}$ & airlines & Archival data & 310 airlines & $\begin{array}{l}\mathrm{L}=\mathrm{O} * \mathrm{~A}, \\
\text { Specialist airlines learn more } \\
\text { from heterogeneous accidents }\end{array}$ \\
\hline Tucker \& Edmondson & $\begin{array}{l}\text { California } \\
\text { Management } \\
\text { Review }\end{array}$ & 2002 & Group & $\mathrm{O}, \mathrm{M}$ & Hospitals & Qualitative & 9 hospitals & No learning \\
\hline Zohar & $\begin{array}{l}\text { Journal of } \\
\text { Organizational } \\
\text { Behavior }\end{array}$ & 2002 & Group & M & Work groups & Survey & 49 groups & $\mathrm{L}=\mathrm{M}$ \\
\hline $\begin{array}{l}\text { Gully, Payne, Kiechel } \\
\text { Koles \& Whiteman }\end{array}$ & $\begin{array}{l}\text { Journal of } \\
\text { Applied } \\
\text { Psychology }\end{array}$ & 2002 & Individual & A & $\begin{array}{l}\text { Undergraduate } \\
\text { students }\end{array}$ & Experiment & 188 & $\mathrm{~L}=\mathrm{A}$ \\
\hline Morey, et al. & $\begin{array}{l}\text { Health } \\
\text { Services } \\
\text { Review }\end{array}$ & 2002 & Group & A & $\begin{array}{l}\text { Emergency } \\
\text { departments in } \\
\text { hospitals }\end{array}$ & $\begin{array}{l}\text { Field } \\
\text { experiment }\end{array}$ & $\begin{array}{l}9 \text { emergency } \\
\text { departments }\end{array}$ & $\mathrm{L}=\mathrm{A}$ \\
\hline Hodgkinson \& Wright & $\begin{array}{l}\text { Organization } \\
\text { Studies }\end{array}$ & 2002 & Team & M & $\begin{array}{l}\text { Top management } \\
\text { teams }\end{array}$ & Qualitative & 1 team & $\mathrm{L}=\mathrm{M}$ \\
\hline
\end{tabular}

\footnotetext{
${ }^{1}$ Please note that this is our interpretation of how to classify a study's mechanisms.
} 


\begin{tabular}{|c|c|c|c|c|c|c|c|c|}
\hline Naquin \& Tynan & $\begin{array}{l}\text { Journal of } \\
\text { Applied } \\
\text { Psychology }\end{array}$ & 2003 & Individual & M & Graduate students & Experiments & 131 & $\mathrm{~L}=\mathrm{M}$ \\
\hline Chuang \& Baum & $\begin{array}{l}\text { Administrative } \\
\text { Science } \\
\text { Quarterly }\end{array}$ & 2003 & Organization & $\mathrm{O}$ & Naming strategy & Archival data & $\begin{array}{l}32 \text { nursing home } \\
\text { chain }\end{array}$ & $\mathrm{L}=\mathrm{O}$ \\
\hline Tjosvold, Yu \& Huy & $\begin{array}{l}\text { Journal of } \\
\text { Management } \\
\text { Studies }\end{array}$ & 2004 & Group & $\mathrm{O}$ and $\mathrm{M}$ & Organization teams & Survey & 107 teams & $\mathrm{L}=\mathrm{M}, \mathrm{O}$ \\
\hline Ellis \& Davidi & $\begin{array}{l}\text { Journal of } \\
\text { Applied } \\
\text { Psychology }\end{array}$ & 2005 & Individual & A & Organizations & Experiment & 98 & $\mathrm{~L}=\mathrm{A}$ \\
\hline $\begin{array}{l}\text { Van Dyck, Frese, } \\
\text { Baer \& Sonnentag }\end{array}$ & $\begin{array}{l}\text { Journal of } \\
\text { Applied } \\
\text { Psychology }\end{array}$ & 2005 & Organization & A & Organizations & Survey & 112 companies & $\mathrm{L}=\mathrm{A}$ \\
\hline Zohar \& Luria & $\begin{array}{l}\text { Journal of } \\
\text { Applied } \\
\text { Psychology }\end{array}$ & 2005 & Multilevel & M & $\begin{array}{l}\text { Production workers } \\
\text { in plants }\end{array}$ & Survey & $\begin{array}{l}3952 \text { individuals in } \\
401 \text { group }\end{array}$ & $\mathrm{L}=\mathrm{M}$ \\
\hline $\begin{array}{l}\text { Ron, Lippshitz \& } \\
\text { Popper }\end{array}$ & $\begin{array}{l}\text { Organization } \\
\text { Studies }\end{array}$ & 2006 & $\begin{array}{l}\text { Group, } \\
\text { organization }\end{array}$ & $\mathrm{M}, \mathrm{A}$ & Fighter crews & $\begin{array}{l}\text { Observations of } \\
\text { after-event } \\
\text { reviews }\end{array}$ & $\begin{array}{l}13 \text { pilots and } \\
\text { navigators }\end{array}$ & $\mathrm{L}=\mathrm{A}, \mathrm{M}$ \\
\hline Neal \& Griffin & $\begin{array}{l}\text { Journal of } \\
\text { Applied } \\
\text { Psychology }\end{array}$ & 2006 & Individual & M & Hospital & $\begin{array}{l}\text { Longitudinal } \\
\text { survey }\end{array}$ & 135 staff & $\mathrm{L}=\mathrm{M}$ \\
\hline Ellis, Mendel \& Nir & $\begin{array}{l}\text { Journal of } \\
\text { Applied } \\
\text { Psychology }\end{array}$ & 2006 & Individual & $\mathrm{M}, \mathrm{A}$ & $\begin{array}{l}\text { Undergraduate } \\
\text { students }\end{array}$ & Experiment & 119 & $\mathrm{~L}=\mathrm{M}, \mathrm{A}$ \\
\hline Tucker \& Spear & $\begin{array}{l}\text { Health } \\
\text { Services } \\
\text { Review }\end{array}$ & 2006 & Multilevel & $\mathrm{O}$ & Nurses in Hospitals & Qualitative & 6 hospitals & $\mathrm{L}=\mathrm{O}$ \\
\hline Baum \& Dahlin & $\begin{array}{l}\text { Organization } \\
\text { Science }\end{array}$ & 2007 & Organization & $\mathrm{O}, \mathrm{M}$ & train accidents & Archival data & 189 railroad years & $\begin{array}{l}\mathrm{L}=\mathrm{M} * \mathrm{O} \\
\text { Underperforming train companies } \\
\text { learn more from others' failure } \\
\text { experiences }\end{array}$ \\
\hline
\end{tabular}




\begin{tabular}{|c|c|c|c|c|c|c|c|c|}
\hline Rathert \& May & $\begin{array}{l}\text { Health Care } \\
\text { Management } \\
\text { Review }\end{array}$ & 2007 & Individual & A & hospitals & Survey & $\begin{array}{l}304 \text { nurses, } 3 \\
\text { hospitals, same chain }\end{array}$ & A gives $M$ \\
\hline Kim \& Miner & $\begin{array}{l}\text { Academy of } \\
\text { Management } \\
\text { Journal }\end{array}$ & 2007 & Organization & $\mathrm{O}$ & $\begin{array}{l}\text { Bank near-failures } \\
\text { and failures }\end{array}$ & Archival data & 2696 banks & $\begin{array}{l}\mathrm{L}=\mathrm{O} \text { with near-failures being the } \\
\text { important events }\end{array}$ \\
\hline Vogus \& Sutcliffe & Medical Care & 2007 & Group & M & Hospitals & Survey & $\begin{array}{l}78 \text { units in } 10 \\
\text { hospitals }\end{array}$ & $\mathrm{L}=\mathrm{M}$ \\
\hline $\begin{array}{l}\text { Malone, Abarca, } \\
\text { Skrepnek, Murphy, } \\
\text { Armstrong, Grizzle, } \\
\text { Rehfeld \& Woosley }\end{array}$ & Medical Care & 2007 & Multilevel & $\mathrm{O}$ & $\begin{array}{l}\text { Pharmacy and } \\
\text { pharmacist }\end{array}$ & $\begin{array}{l}\text { Survey + } \\
\text { archival }\end{array}$ & 672 pharmacies & $\mathrm{L}=\mathrm{O}$ \\
\hline $\begin{array}{l}\text { Stern, Katz-Navon \& } \\
\text { Naveh }\end{array}$ & $\begin{array}{l}\text { Management } \\
\text { Science }\end{array}$ & 2008 & Individual & $\mathrm{O}$ & $\begin{array}{l}\text { Residents in } 25 \\
\text { departments of two } \\
\text { teaching hospitals }\end{array}$ & Survey & 123 resdients & $\mathrm{L}=\mathrm{O}$ \\
\hline Dillon \& Tinsley & $\begin{array}{l}\text { Management } \\
\text { Science }\end{array}$ & 2008 & Individual & M & Students and NASA & Experiment & 292 & $\mathrm{~L}=\mathrm{M}$ \\
\hline Thornlow \& Merlin & $\begin{array}{l}\text { Health Care } \\
\text { Management } \\
\text { Review }\end{array}$ & 2009 & Organization & A & hospital routines & Archival data & $\begin{array}{l}1430981 \text { patient } \\
\text { records, } 115 \\
\text { hospitals, } 20 \text { states }\end{array}$ & $\mathrm{L}=\mathrm{A}$ as a function of procedure \\
\hline Rhee & $\begin{array}{l}\text { Journal of } \\
\text { Management } \\
\text { Studies }\end{array}$ & 2009 & Organization & M & Car recalls & Archival data & 54 U.S. automakers & $\mathrm{L}=\mathrm{M}$, inverted $\mathrm{U}$ \\
\hline Madsen & $\begin{array}{l}\text { Organization } \\
\text { Science }\end{array}$ & 2009 & Organization & $\mathrm{O}$ & Mining accidents & Archival data & Recency of events & $\mathrm{L}=\mathrm{O}$ \\
\hline Kerr & $\begin{array}{l}\text { Social Science } \\
\text { and Medicine }\end{array}$ & 2009 & Group & $\mathrm{O}, \mathrm{M}$ & Hospitals & Qualitative & 2 clinics & $\mathrm{L}=\mathrm{O}+\mathrm{M}$ \\
\hline Carmeli \& Gittell & $\begin{array}{l}\text { Journal of } \\
\text { Organizational } \\
\text { Behavior }\end{array}$ & 2009 & Individual & M, A & $\begin{array}{l}\text { Organizations and } \\
\text { graduate students }\end{array}$ & Survey & 228 & $\mathrm{~L}=\mathrm{M}+\mathrm{A}$ \\
\hline $\begin{array}{l}\text { Katz-Navon, Naveh \& } \\
\text { Stern }\end{array}$ & $\begin{array}{l}\text { Journal of } \\
\text { Applied } \\
\text { Psychology }\end{array}$ & 2009 & Group & M & Hospitals & Survey & $\begin{array}{l}123 \text { residents, } 25 \\
\text { medical wards }\end{array}$ & $\mathrm{L}=\mathrm{M}$ \\
\hline
\end{tabular}




\begin{tabular}{|c|c|c|c|c|c|c|c|c|}
\hline Madsen \& Desai & $\begin{array}{l}\text { Academy of } \\
\text { Management } \\
\text { Journal }\end{array}$ & 2010 & Organization & $\mathrm{O}$ & Orbital launch & Archival data & $\begin{array}{l}26 \text { launch vehicle } \\
\text { organizations }\end{array}$ & $\mathrm{L}=\mathrm{O}$ \\
\hline $\begin{array}{l}\text { Ginsburg, Chuang, } \\
\text { Berta, Norton, Ng, } \\
\text { Tregunno \& } \\
\text { Richardson }\end{array}$ & $\begin{array}{l}\text { Health } \\
\text { Services } \\
\text { Research }\end{array}$ & 2010 & Organization & A & Patient safety & Survey & 69 hospitals & $\mathrm{L}=\mathrm{A}$ \\
\hline Desai & $\begin{array}{l}\text { Academy of } \\
\text { Management } \\
\text { Journal }\end{array}$ & 2011 & $\begin{array}{l}\text { Press release } \\
\text { Organization }\end{array}$ & $\mathrm{O}, \mathrm{M}$ & Railroad accidents & Archival data & $\begin{array}{l}234 \text { press releases, } \\
391 \text { firm-years }\end{array}$ & $\mathrm{L}=\mathrm{M}, \mathrm{O}$ \\
\hline Mitsuhashi & $\begin{array}{l}\text { Industrial and } \\
\text { Corporate } \\
\text { Change }\end{array}$ & 2011 & Organization & $\mathrm{M}$ and $\mathrm{O}$ & $\begin{array}{l}\text { Japanese nuclear } \\
\text { plants }\end{array}$ & Archival data & 56 reactors & $\mathrm{L}=\mathrm{M}, \mathrm{O}$ has no effect \\
\hline Banja & $\begin{array}{l}\text { Business } \\
\text { Horizons }\end{array}$ & 2011 & Event & $\mathrm{A}, \mathrm{M}$ & Health care & $\begin{array}{l}\text { Case histories } \\
\text { and theory }\end{array}$ & $\begin{array}{l}\text { Description of } \\
\text { systematic rule } \\
\text { breaking }\end{array}$ & $\mathrm{L}=\mathrm{M}, \mathrm{A}$ \\
\hline Zhao & $\begin{array}{l}\text { Journal of } \\
\text { Organizational } \\
\text { Behavior }\end{array}$ & 2011 & Individual & M & $\begin{array}{l}\text { Undergraduate } \\
\text { students }\end{array}$ & $\begin{array}{l}\text { Survey with } \\
\text { experiment }\end{array}$ & 127 & $\mathrm{~L}=\mathrm{M}$ \\
\hline $\begin{array}{l}\text { Shepherd, Patzelt \& } \\
\text { Wolfe }\end{array}$ & $\begin{array}{l}\text { Academy of } \\
\text { Management } \\
\text { Journal }\end{array}$ & 2011 & Individual & $\mathrm{M}, \mathrm{A}$ & Research institutes & Survey & 585 & $\mathrm{~L}=\mathrm{M}+\mathrm{A}+\mathrm{M} * \mathrm{~A}$ \\
\hline $\begin{array}{l}\text { Downey, Hernandez- } \\
\text { Boussard, Banka \& } \\
\text { Morton }\end{array}$ & $\begin{array}{l}\text { Health } \\
\text { Services } \\
\text { Research }\end{array}$ & 2012 & Procedure & $\begin{array}{l}\text { Trends, no } \\
\text { mechanism }\end{array}$ & $\begin{array}{l}\text { Medical failure } \\
\text { trends using US } \\
\text { national data }\end{array}$ & Archival data & $\begin{array}{l}7.6 \text { million adverse } \\
\text { events for } 69 \text { million } \\
\text { hospitalizations }\end{array}$ & $\begin{array}{l}14 \text { procedures: } 6 \text { with decrease } 1 \text { witl } \\
\text { no change and } 7 \text { with increases in } \\
\text { adverse events }\end{array}$ \\
\hline $\begin{array}{l}\text { Muehlfeld, Sahib \& } \\
\text { Van Witteloostujin }\end{array}$ & $\begin{array}{l}\text { Strategic } \\
\text { Management } \\
\text { Journal }\end{array}$ & 2012 & Transaction & $\mathrm{O}$ & $\begin{array}{l}\text { Newspaper merger } \\
\text { and acquisitions }\end{array}$ & Archival data & $\begin{array}{l}4973 \text { m\&a attempts } \\
1981-2008 \text { by } 1964 \\
\text { firms }\end{array}$ & $\mathrm{L}=\mathrm{O}, \mathrm{U}$-shaped relationship \\
\hline $\begin{array}{l}\text { Buljac-Samardzic, } \\
\text { Van Woerkom \& } \\
\text { Paauwe }\end{array}$ & $\begin{array}{l}\text { Health Care } \\
\text { Management } \\
\text { Review }\end{array}$ & 2012 & Group & A & Hospitals & Survey & 152 teams & $\mathrm{L}=\mathrm{A}$ \\
\hline
\end{tabular}




\begin{tabular}{|c|c|c|c|c|c|c|c|c|}
\hline $\begin{array}{l}\text { Lawton, Carruthers, } \\
\text { Gardner, Wright \& } \\
\text { Mceachan }\end{array}$ & $\begin{array}{l}\text { Health } \\
\text { Services } \\
\text { Research }\end{array}$ & 2012 & Group & $\mathrm{O}, \mathrm{A}$ & Hospitals & Qualitative & 3 wards & $\mathrm{L}=\mathrm{O} * \mathrm{~A}$ \\
\hline Stan \& Vermeulen & $\begin{array}{l}\text { Management } \\
\text { Science }\end{array}$ & 2013 & Organization & $\mathrm{O}$ & Fertility clinics & Archival data & $\begin{array}{l}116 \text { UK fertility } \\
\text { clinics 1991-2006 }\end{array}$ & O--> A --> L \\
\hline $\begin{array}{l}\text { Zheng, Miner \& } \\
\text { George }\end{array}$ & $\begin{array}{l}\text { Industrial and } \\
\text { Corporate } \\
\text { Change }\end{array}$ & 2013 & $\begin{array}{l}\text { Patent (IVs on } \\
\text { individual and } \\
\text { group levels) }\end{array}$ & $\mathrm{M}, \mathrm{O}$ & $\begin{array}{l}\text { University } \\
\text { technology transfer } \\
\text { office }\end{array}$ & $\begin{array}{l}\text { Archival and } \\
\text { interviews }\end{array}$ & $\begin{array}{l}778 \text { patents of which } \\
170 \text { were licensed }\end{array}$ & $\mathrm{L}=\mathrm{M} * \mathrm{O}$ \\
\hline Kc, Staat \& Gino & $\begin{array}{l}\text { Management } \\
\text { Science }\end{array}$ & 2013 & Individual & $\mathrm{O}, \mathrm{M}$ & Hospitals & Archival data & 71 cardiac surgeons & $\mathrm{L}=\mathrm{O}+\mathrm{M}+\mathrm{M} * \mathrm{O}$ \\
\hline Desai & $\begin{array}{l}\text { Journal of } \\
\text { Management }\end{array}$ & 2014 & Organization & M & $\begin{array}{l}\text { Air traffic } \\
\text { controllers, near } \\
\text { misses }\end{array}$ & Archival data & $\begin{array}{l}\text { US class I railroad } \\
\text { firms }\end{array}$ & $\mathrm{L}=\mathrm{M}$ \\
\hline $\begin{array}{l}\text { Haunschild, Polodori } \\
\text { \& Chandler }\end{array}$ & $\begin{array}{l}\text { Organization } \\
\text { Science }\end{array}$ & 2015 & Organization & $\mathrm{O}$ & $\begin{array}{l}\text { Pharmaceutical } \\
\text { firms, drug recalls }\end{array}$ & Archival data & 146 firms & $\begin{array}{l}\mathrm{L}=\mathrm{O}, \mathrm{M} \\
\text { Motivation varies over } \\
\text { Time. }\end{array}$ \\
\hline Eggers \& Song & $\begin{array}{l}\text { Academy of } \\
\text { Management } \\
\text { Journal }\end{array}$ & 2015 & Individual & $\mathrm{M}, \mathrm{A}$ & $\begin{array}{l}\text { Serial entrepreneurs } \\
\text { in China }\end{array}$ & Survey & 253 entrepreneurs & $\mathrm{L}=\mathrm{M}$, A tested, no learning \\
\hline Probst & $\begin{array}{l}\text { Journal of } \\
\text { Applied } \\
\text { Psychology }\end{array}$ & 2015 & Individual & M & 33 organizations & Survey & 1238 & $\mathrm{~L}=\mathrm{M}$ \\
\hline Desai & $\begin{array}{l}\text { Academy of } \\
\text { Management } \\
\text { Journal }\end{array}$ & 2015 & Organization & $\mathrm{O}$ & $\begin{array}{l}\text { Heart bypass } \\
\text { surgeries }\end{array}$ & Archival data & 116 hospitals & $\mathrm{L}=\mathrm{O}$ \\
\hline $\begin{array}{l}\text { Madsen, Dillon \& } \\
\text { Tinsley }\end{array}$ & Risk Analysis & 2016 & Organization & $\mathrm{O}$ & Airlines & Archival data & $\begin{array}{l}64 \text { commercial } \\
\text { airlines }\end{array}$ & $\mathrm{L}=\mathrm{O}$ \\
\hline
\end{tabular}




\begin{tabular}{|c|c|c|c|c|c|c|c|c|}
\hline $\begin{array}{l}\text { Khanna, Guler \& } \\
\text { Kerkar }\end{array}$ & $\begin{array}{l}\text { Academy of } \\
\text { Management } \\
\text { Journal }\end{array}$ & 2016 & Organization & $\mathrm{O}$ & $\begin{array}{l}\text { Pharmaceutical } \\
\text { industry }\end{array}$ & Archival data & $\begin{array}{l}97 \text { pharmaceutical } \\
\text { firms }\end{array}$ & $\mathrm{L}=\mathrm{O}$ \\
\hline Desai & $\begin{array}{l}\text { Industrial and } \\
\text { Corporate } \\
\text { Change }\end{array}$ & 2016 & Organization & $\mathrm{O}$ & Railroad accident & Archival data & US railroad firms & $\mathrm{L}=\mathrm{O}$ \\
\hline
\end{tabular}

